\title{
SDGs 지표 데이터 이용가능성(Data Availability) 분석
}

\section{목차}

I. 서론

II. 분석 방법 개괄

1. 분석대상

2. 분석자료

3. 분석방법

III. SDGs 지표의 실제 데이터 이용가능성(Data Availability)

1. SDGs Tier별 구성 분석

2. Data Accessibility 분석

3. Country Coverage 분석

4. Data Frequency 분석

5. 종합 분석: Data Availability

IV. 결어

주제어: 지속가능개발목표(SDGs), 데이터 이용가능성(Data Availability), 데이터 접근성(Data Accessibility), 국가포함수준(Country Coverage), 데이터 빈도수(Data Frequency)

\section{I. 서론}

지난 2015년 9월 UN총회에서 SDGs 16개 목표(goals)와 169개 세부목표(targets)가 공식 채 택되고, 최근 3월 유엔통계위원회(UN Statistical Commission, 이하 UNSC)에서 동 SDGs 이 행 및 평가를 위한 230개(중복지표 포함 241개)를 발표함에 따라 SDGs를 구성하는 목표 및 세 
부목표, 지표까지 전체적인 체계가 완성적인 모습을 갖추게 되었다. 그리고 이제 국제사회는 이러 한 SDGs의 효과적인 이행과 모니터링을 위한 지표체제를 확립하는데 힘쓰고 있다.

이를 위해 UNSC는 2015년 3월, 산하에 지속가능발전목표 지표에 관한 기관간 전문가그룹 (Inter-Agency and Expert Group on SDGs Indicators, 이하 IAEG-SDGs) 을 수립하고, 지 난 1 년여 기간 동안 각 지표에 대한 데이터 측정 방법론 뿐만 아니라 데이터 이용가능 여부에 따 라 지표를 분류하는 Tier system을 마련하는 등 완성도 있는 글로벌 지표 체계를 수립하기 위해 지속적으로 노력해오고 있다.

최종지표 선정과정에서 합의된 고려요소는 (1) 목표(goals) 및 세부목표(targets)와의 연관성, (2) 방법론적 정당성, (3) 측정가능성, (4) 접근가능성, (5) 지표 전체 개수의 제한(전체 230 개 개수 유지), (6) 각 지표들의 글로벌 차원에서의 성과(outcome) 등 총 여섯 가지1)로, IAEG-SDGs는 이러한 요소에 의거하여 총 230개(중복포함 241개) 지표를 확정하였다. 아울러 IAEG-SDGs는 각 지표의 방법론 및 국제적 합의 기준 보유 유무 및 데이터 이용가능성 수준에 따라 230개 지표 를 각각 Tier1, Tier2, Tier3으로 분류하였다. 여기서 Tier1은 방법론 및 국제적 기준이 이미 존 재하고 UN 회원국 193 개에 대해 지속적으로 데이터를 확보할 수 있는 지표를 의미하고 있으며, IAEG-SDGs는 96개(중복포함 98개) 지표를 Tier1으로 지정하였다.

그렇다면, 과연 최종 합의된 230 개 지표에 대한 데이터가 얼마나 이용가능한지, 특히 지표의 데이터에 대한 접근 방법론 및 국제적 기준이 합의되어 있고 대상 국가들로부터 지속적으로 데이 터 확보가 가능하다고 분류됨으로써 비교적 가장 안정적인 데이터 체계가 구축되어 있다고 평가 할 수 있는 Tier1 지표들의 경우, 실제 얼마나 데이터 이용가능성(data availability)이 제대로 보장되는지에 대해 문제의식을 가지고 살펴볼 필요가 있다.

본 고에서는 이러한 문제의식에 기반하여 최근 3월 공개된 IAEG-SDGs 보고서에서 제시된 Tier1 지표들을 대상으로 실제 제시된 데이터에 얼마나 접근 가능한지(data accessibility), 그리 고 193개 UN 회원국 전체 중 얼마나 많은 국가에 대한 데이터를 얻을 수 있는지(country coverage), 그리고 해당 국가들의 데이터 이용가능 연수는 얼마나 충분한지(data frequency) 등 을 순차적으로 살펴봄으로써 Tier2, Tier3 지표들에 비해 가장 데이터 이용가능성이 높아야할 것 으로 기대되는 Tier1 지표들의 실제는 어떠한지 분석하고자 한다. 이를 통해 동 연구에서는 $\mathrm{SDGs}$ 지표의 데이터 이용가능성과 실제간의 간극(gap)이 존재하는지 여부를 살펴봄으로써 글로 벌 지표 체계 수립 과정에서의 우리의 현 위치를 점검하는 것을 목표로 한다. 아직 SDGs 글로벌

1) 지난 2015년 2월 개최된 46차 UNSC 전문가그룹 회의(UNSC Expert Gorup Meeting)에서는 최종 지표 선정시, 상기의 여섯가지 고려요소에 기반할 것에 합의하였다. (출처: http://sd.iisd.org/news/sdg-group-discusses-indicatorselection-way-forward/) 
지표 체계는 완성된 단계가 아니며, 현재도 IAEG-SDGs는 데이터 tier system 분류에 따라 방 법론 및 데이터 이용가능성을 개선하고자 노력하고 있다. 따라서 지표 체계 수립과정에서의 현 위치를 파악하는 작업은 보다 완성도 높은 지표 체계를 마련하는데 있어 문제점 및 개선방향을 명확히 하는데 좋은 기반이 될 수 있다는 점에서 유의미하다고 할 수 있을 것이다.

이를 위해 본 연구에서는 우선 동 연구의 분석 대상 및 분석 자료, 분석 방법이 무엇인지에 대 해 개괄적인 소개를 먼저 한 뒤, SDGs Tier별 구성 분석 및 데이터 접근성(data accessibility) 분석을 통해 분석 가능 대상 지표를 우선 분류한 뒤, 국가포함수준(country coverage) 분석 및 데이터 빈도수(data frequency) 분석을 통해 대상 지표들의 각 분석 현황이 어떠한지를 살펴본 후 두 기준을 통해 도출된 결과들간의 상관관계를 살펴봄으로써 대상지표들의 데이터 이용가능성 (data availability)이 어떠한지에 대해 종합 결과를 도출하는 순으로 진행된다.

\section{II. 분석 방법 개괄}

\section{1. 분석 대상}

IAEG-SDGs는 SDGs 230개(중복포함 241개) 지표 전체에 대해 데이터 방법론 및 국제적 기 준 수립 여부, 그리고 데이터 이용가능성 여부에 따라 Tier 구분을 두고 있다. 아래〈표 1〉에서 볼 수 있는 바와 같이, Tier1은 데이터 측정 방법론 및 국제적 기준이 존재하고 정기적으로 데이 터 생산이 가능하다고 평가되는 지표들이며, Tier2는 데이터 측정 방법론 및 국제적 기준은 존재 하나 지속적인 데이터 생산이 어렵다고 판단되는 지표를 말하며, Tier3은 데이터 측정 방법론 및 국제적 기준 자체가 아직 확립되어 있지 않은 가장 완성도가 낮은 지표들을 말한다. 또한 현재 지표 분류 여부가 논의 중에 있는 지표들의 경우 Tier $1 / 2$ 또는 Tier $1 / 2 / 3$, Untiered 등으로 잠 정 분류되어 있다.

〈표 1〉SDGs Tier system 구성

\begin{tabular}{c|l}
\hline 구 분 & \multicolumn{1}{c}{ 내 용 } \\
\hline Tier1 & $\begin{array}{l}\text { 지표의 개념이 명확하며, 데이터에 대한 획득 방법론 및 국제적 기준이 확립되어 있으며, 각 회 } \\
\text { 원국들로부터 주기적으로 데이터가 생산가능한 지표 }\end{array}$ \\
\hline Tier2 & $\begin{array}{l}\text { 지표의 개념이 명확하고, 데이터에 대한 획득 방법론 및 국제적 기준이 확립되어 있으나, 각 회 } \\
\text { 원국들로부터 주기적인 데이터 생산이 어려운 지표 }\end{array}$ \\
\hline Tier3 & $\begin{array}{l}\text { 현재 데이터에 대한 획득 방법론 및 국제적 기준이 확립되어 있지 않거나 현재 개발/테스트 중 } \\
\text { 에 있는 지표 }\end{array}$ \\
\hline
\end{tabular}

출처: IAEG-SDGs (2016) 
동 연구에서는 이 중에서도 우선 데이터 측정 방법론이 존재하고 정기적으로 데이터 수집이 가 능하다고 분류되는 Tier1 지표와 Tier1/2 지표를 1차적인 대상지표로 한다. Tier1/2 지표의 경 우, 현재 Tier 설정에 있어 Tier1 또는 Tier2 여부에 대해 아직 고려 중에 있는 지표들로서, 추 후 Tier1 지표로 고려될 가능성이 높다는 점에서 동 연구에서의 분석 대상으로 함께 포함시키고 자 한다.

이를 통해 동 연구에서는 Tier1과 Tier1/2 지표를 대상으로 SDGs 지표의 데이터 이용가능성 과 실제 간의 간극(gap)이 존재하는지 여부를 살펴봄으로써 글로벌 지표 체계 수립 과정에서의 우리의 현 위치를 점검하는 것을 목표로 한다.

\section{2. 분석 자료}

동 연구에서는 지난 3 월 공개된 IAEG-SDGs 보고서를 기본 분석자료로 한다. IAEG-SDGs에 서는 IAEG-SDGs 3차 회의 논의를 위해 'Provisional Proposed Tiers for Global SDG Indicators- as of March 24, 2016' 보고서를 작성 및 공개하였다. 본 보고서에는 230개 전체 지표에 대한 Tier 구성 및 데이터 담당기관, 데이터 측정 방법론을 비롯한 데이터 이용가능성 등 에 대한 세부 설명을 명시해두고 있으며, 이는 동 연구에서의 주요 기본 자료가 된다.

이와 함께 동 연구에서는 Casey Dunning과 Jared Kalow2)가 글로벌개발센터(Center for Global Development, CGD) 웹사이트 블로그란에 두 차례에 걸쳐 게시한 자료를 참조한다. Dunning과 Kalow는 지난 5월과 6월, 'SDG Indicators: Serious Gaps Abound in Data Availability'과 'What SDGs Can We Track Now?'라는 제목으로 SDGs 지표의 데이터 이용가 능성이 어떠한지에 대한 분석자료를 게시한 바 있다. 동 연구의 문제의식 역시도 동 블로그 분석 글에 기반하고 있음을 밝힌다. 이에 동 연구에서의 전체적인 분석 흐름 및 분석틀의 개념 역시도 Dunning and Kalow의 분석 방법과 기본적으로 동일하다.

다만 동 분석자료의 내용을 세부적으로 살펴보는 과정에서, Dunning Kalow가 제시한 5월과 6 월 분석 내용상의 불일치로 인한 오류, 6 월 자료에서 제시하고 있는 대상지표와 데이터의 분류 및 내용상의 오류 등이 발견됨에 따라 동 연구에서는 오류 부분에 대한 수정 및 보완작업이 이루 어졌다. 이로 인해 Dunning and Kalow가 분석대상으로 하고 있는 총 지표의 개수(72개)와 동 연구에서의 분석대상 지표 개수(73개)상의 차이가 존재하며, 대상지표의 구성 상에도 차이가 존 재한다. 또한 동 자료는 분석의 결과를 중심으로 제시하고 있다는 점에서 본 연구에서는 분석 과

2) Casey Dunning는 현재 글로벌개발센터(Center for Global Development) 선임 정책분석관(Senior Policy Analysis)이며, Jared Kalow는 동 센터 소속 연구보조(Research Assistant)으로 재직중임. 
정 및 개념을 재정리하고 세부 분석 기준을 새로이 추가함으로써 각 분석 단계별 방법 및 내용을 보다 정교하게 살펴볼 수 있도록 하였다.

따라서 동 연구에서는 Dunning and Kalow 분석 자료에 기반하여 문제의식 및 분석 흐름 및 개념 설정을 하고 있으나, 자료상의 오류로 인해 동 분석자료는 참조용으로 쓰되, 1,2 차 자료상 의 불일치 부분 및 데이터 오류는 수정을 통해 반영하였다고 할 수 있다. 그리고 이러한 수정 및 보완작업을 위한 기준은 IAEG-SDGs(2016) 보고서에 기반한다.

\section{3. 분석 방법}

\section{가. 데이터 접근성(Data Accessibility)}

상기 분석대상 관련 부분에서 언급한 바와 같이, SDGs 지표들의 데이터 이용가능성을 살펴보 기 위해 Tier1, Tier1/2에 해당하는 총 101 개 지표를 1 차적인 대상지표로 한다. 동 연구의 취지 가 이러한 지표의 데이터 이용가능성이 가장 높다고 간주되는 Tier1, 그리고 Tier $1 / 2$ 지표들의 실제는 어떠한지를 살펴보는 것이라는 점에서, 데이터 이용가능성을 구성하는 세부 기준들, 즉 데 이터 접근성(Data Accessibility), 국가포함수준(Country Coverage), 데이터 빈도수(Data Frequency) 각각의 현황을 분석한다.

우선 동 단계에서는 IAEG-SDGs(2016.03) 보고서 상에 각 지표별로 제시되어 있는 정보에 기반하여 (1) 방법론(methodology) 존재여부 (기 테스트 여부 포함), (2) 동 방법론에 대한 국제적 기준(international Standard) 수립 여부, (3) 메타데이터(meta data) 보유 여부, (4) 데이터베이 스(database) 보유 여부 등 4가지 기준으로 데이터 접근성(data accessibility)을 종합적으로 살 펴보았다. 따라서 데이터 접근성(data accessibility,이하 data accessibility)이란, 위의 네 가지 기준을 모두 충족함으로써 실질적으로 지표에 해당하는 접근가능한 데이터를 확보하고 있는 상태 로 정의할 수 있다. 이에 따라 위 네 가지 요소 중 한 가지 요소라도 미충족될 경우 현재로서는 해당 지표에 대한 명확한 기준에 따른 데이터 확보가 어려운 지표라고 해석한다.

\section{나. 국가포함수준(Country Coverage)}

국가포함수준(Country Coverage. 이하 country coverage)이란 총 193개 UN 회원국 중 2000년 2015년 사이에 한 해라도 데이터가 제공되는 국가의 비중(\%)으로 정의한다. 즉 현재 $\mathrm{SDGs}$ 지표의 이행에 대한 모니터링 및 보고 의무가 있는 총 193 개 UN 회원국을 대상으로(〈표 3) 참조), data accessibility을 확보한 지표들 각각에 대해 얼마나 많은 국가들이 데이터를 제공 
할 수 있는지에 초점을 맞추어 살펴보는 것이다. 각 지표별 국가 포함 비중은 최소값 $0 \%$ 에서 최 대값 $100 \%$ 를 가진다.

이러한 country coverage의 특징을 보다 효과적으로 분석 및 설명하기 위해 각 지표별 country coverage를 $25 \%$ 단위 기준으로 4가지 점수화를 시도하였다(〈표 2〉참조). 먼저 전체 193 개국 기준, $25 \%$ 미만의 국가들을 포함할 경우 very poor로, $25 \%$ 이상 $50 \%$ 미만의 국가를 포함할 경우 quite poor, $50 \%$ 이상 $75 \%$ 미만은 quite good, 그리고 $75 \%$ 이상 $100 \%$ 이하는 very good으로 분류하였다. 이러한 점수화 분류결과를 대상지표 전체 차원 및 SDGs 17 개 목표 별 차원에서 각각 살펴봄으로써 어떠한 특징을 갖는지 분석하였다.

〈표 2〉국가포함수준(Country Coverage) 점수화 기준

\begin{tabular}{c|c}
\hline 등급 & 점수 \\
\hline Very good & $75<\mathrm{a} \leq 100$ \\
\hline Quite good & $50<\mathrm{a} \leq 75$ \\
\hline Quite poor & $25<\mathrm{a} \leq 50$ \\
\hline very poor & $0<\mathrm{a} \leq 25$ \\
\hline
\end{tabular}

출처: 저자 작성

〈표 3〉UN 회원국 리스트 (총 193개국)

\begin{tabular}{|c|c|c|c|c|c|c|c|}
\hline no. & 국가명 & no. & 국가명 & no. & 국가명 & no. & 국가명 \\
\hline 1 & Afghanistan & 50 & Dominica & 99 & Lithuania & 148 & Sao Tome and Principe \\
\hline 2 & Albania & 51 & Dominican Republic & 100 & Luxembourg & 149 & Saudi Arabia \\
\hline 3 & Algeria & 52 & Ecuador & 101 & Madagascar & 150 & Senegal \\
\hline 4 & Andorra & 53 & Egypt & 102 & Malawi & 151 & Serbia \\
\hline 5 & Angola & 54 & El Salvador & 103 & Malaysia & 152 & Seychelles \\
\hline 6 & $\begin{array}{c}\text { Antigua and } \\
\text { Barbuda }\end{array}$ & 55 & Equatorial Guinea & 104 & Maldives & 153 & Sierra Leone \\
\hline 7 & Argentina & 56 & Eritrea & 105 & Mali & 154 & Singapore \\
\hline 8 & Armenia & 57 & Estonia & 106 & Malta & 155 & Slovakia \\
\hline 9 & Australia & 58 & Ethiopia & 107 & Marshall Islands & 156 & Slovenia \\
\hline 10 & Austria & 59 & Fiji & 108 & Mauritania & 157 & Solomon Islands \\
\hline 11 & Azerbaijan & 60 & Finland & 109 & Mauritius & 158 & Somalia \\
\hline 12 & Bahamas & 61 & France & 110 & Mexico & 159 & South Africa \\
\hline 13 & Bahrain & 62 & Gabon & 111 & Micronesia & 160 & South Sudan \\
\hline 14 & Bangladesh & 63 & Gambia & 112 & Monaco & 161 & Spain \\
\hline 15 & Barbados & 64 & Georgia & 113 & Mongolia & 162 & Sri Lanka \\
\hline 16 & Belarus & 65 & Germany & 114 & Montenegro & 163 & Sudan \\
\hline 17 & Belgium & 66 & Ghana & 115 & Morocco & 164 & Suriname \\
\hline 18 & Belize & 67 & Greece & 116 & Mozambique & 165 & Swaziland \\
\hline
\end{tabular}




\begin{tabular}{|c|c|c|c|c|c|c|c|}
\hline no. & 국가명 & no. & 국가명 & no. & 국가명 & no. & 국가명 \\
\hline 19 & Benin & 68 & Grenada & 117 & Myanmar & 166 & Sweden \\
\hline 20 & Bhutan & 69 & Guatemala & 118 & Namibia & 167 & Switzerland \\
\hline 21 & Bolivia & 70 & Guinea & 119 & Nauru & 168 & Syrian Arab Republic \\
\hline 22 & $\begin{array}{l}\text { Bosnia and } \\
\text { Herzegovina }\end{array}$ & 71 & Guinea Bissau & 120 & Nepal & 169 & Tajikistan \\
\hline 23 & Botswana & 72 & Guyana & 121 & Netherlands & 170 & Thailand \\
\hline 24 & Brazil & 73 & Haiti & 122 & New Zealand & 171 & $\begin{array}{l}\text { The former Yugoslav } \\
\text { Republic of Macedonia }\end{array}$ \\
\hline 25 & $\begin{array}{c}\text { Brunei } \\
\text { Darussalam }\end{array}$ & 74 & Honduras & 123 & Nicaragua & 172 & Timor-Leste \\
\hline 26 & Bulgaria & 75 & Hungary & 124 & Niger & 173 & Togo \\
\hline 27 & Burkina Faso & 76 & Iceland & 125 & Nigeria & 174 & Tonga \\
\hline 28 & Burundi & 77 & India & 126 & Norway & 175 & Trinidad and Tobago \\
\hline 29 & Cabo Verde & 78 & Indonesia & 127 & Oman & 176 & Tunisia \\
\hline 30 & Cambodia & 79 & $\begin{array}{l}\text { Iran (Islamic } \\
\text { Republic of) }\end{array}$ & 128 & Pakistan & 177 & Turkey \\
\hline 31 & Cameroon & 80 & Iraq & 129 & Palau & 178 & Turkmenistan \\
\hline 32 & Canada & 81 & Ireland & 130 & Panama & 179 & Tuvalu \\
\hline 33 & $\begin{array}{c}\text { Central African } \\
\text { Republic }\end{array}$ & 82 & Israel & 131 & Papua New Guinea & 180 & Uganda \\
\hline 34 & Chad & 83 & Italy & 132 & Paraguay & 181 & Ukraine \\
\hline 35 & Chile & 84 & Jamaica & 133 & Peru & 182 & United Arab Emirates \\
\hline 36 & China & 85 & Japan & 134 & Philippines & 183 & $\begin{array}{l}\text { United Kingdom of Great } \\
\text { Britain and Northern Ireland }\end{array}$ \\
\hline 37 & Colombia & 86 & Jordan & 135 & Poland & 184 & $\begin{array}{c}\text { United Republic of } \\
\text { Tanzania }\end{array}$ \\
\hline 38 & Comoros & 87 & Kazakhstan & 136 & Portugal & 185 & United States of America \\
\hline 39 & Congo & 88 & Kenya & 137 & Qatar & 186 & Uruguay \\
\hline 40 & Costa Rica & 89 & Kiribati & 138 & Republic of Korea & 187 & Uzbekistan \\
\hline 41 & Côte D'Ivoire & 90 & Kuwait & 139 & Republic of Moldova & 188 & Vanuatu \\
\hline 42 & Croatia & 91 & Kyrgyzstan & 140 & Romania & 189 & $\begin{array}{c}\text { Venezuela, Bolivarian } \\
\text { Republic of } \\
\end{array}$ \\
\hline 43 & Cuba & 92 & Lao PDR & 141 & Russian Federation & 190 & Viet Nam \\
\hline 44 & Cyprus & 93 & Latvia & 142 & Rwanda & 191 & Yemen \\
\hline 45 & Czech Republic & 94 & Lebanon & 143 & Saint Kitts and Nevis & 192 & Zambia \\
\hline 46 & $\begin{array}{c}\text { Democratic } \\
\text { People's Republic } \\
\text { of Korea }\end{array}$ & 95 & Lesotho & 144 & Saint Lucia & 193 & Zimbabwe \\
\hline 47 & DR Congo & 96 & Liberia & 145 & $\begin{array}{c}\text { Saint Vincent and the } \\
\text { Grenadines }\end{array}$ & & \\
\hline 48 & Denmark & 97 & Libya & 146 & Samoa & & \\
\hline 49 & Djibouti & 98 & Liechtenstein & 147 & San Marino & & \\
\hline
\end{tabular}

제 I 장

제 II 장

출처: UN홈페이지 (http://un.org) 


\section{다. 데이터 빈도수(Data Frequency)}

상기 ‘country coverage' 분석 기준과 함께, 세 번째 분석기준으로서 ‘데이터 빈도수(data frequency)'를 살펴본다. 데이터 빈도수(data frequency, 이하 data frequency)란, 각 지표별로 한 해라도 데이터를 제공한 193 개 UN 회원국들의 평균 데이터 제공 연수로 정의하며, 동 기준을 통해 얼마나 각국의 데이터를 안정적으로 활용할 수 있는지를 살펴본다.

동 측정 지수의 최소값은 0 개년, 최대값은 16 개년을 가지며, 보다 효과적인 분석 및 설명을 위 해 'country coverage' 기준과 마찬가지로 아래와 같이 각 지표별로 4개년 단위 기준으로 4가지 점수화를 시도하였다(〈표 4〉 참조). 먼저 동 연구에서는 2000년 이후 자료를 기준으로 2015년까 지 총 16 개년 자료를 대상으로 하며, 4 개년 미만의 연수(data point)의 데이터를 가질 경우 very poor로, 4 개년 이상 8개년 미만 연수의 데이터를 가질 경우 quite poor, 8개년 이상 12 개년 미 만은 quite good, 그리고 12 개년 이상 16 개년 이하는 very good으로 분류하였다. 이러한 점수 화 분류결과를 대상지표 전체차원 및 SDGs 17 개 목표별 차원에서 각각 살펴봄으로써 어떠한 특 징을 갖는지 분석하였다.

〈표 4〉데이터 빈도수(Data Frequency) 점수화 기준

\begin{tabular}{c|c}
\hline 등급 & 점수 \\
\hline very good & $12<\mathrm{a} \leq 16$ \\
\hline quite good & $8<\mathrm{a} \leq 12$ \\
\hline quite poor & $4<\mathrm{a} \leq 8$ \\
\hline very poor & $0<\mathrm{a} \leq 4$ \\
\hline
\end{tabular}

출처: 저자 작성

\section{라. 데이터 이용가능성(Data Availability)}

데이터 이용가능성(Data Availability, 이하 data availability)이란, 상기의 country coverage 및 data frequency의 점수를 종합적으로 고려하여 얼마나 많은 대상국가들로부터 얼마나 오랜 기간 동안 안정적으로 데이터를 획득할 수 있는가를 말한다. 따라서 country coverage와 data frequency 모두가 높을수록 data availability은 높다고 할 수 있으며, 반대일 경우 전반적으로 낮다는 평가가 가능하다.

동 단계에서는 종합적인 분석 결과를 도출하기 위해 country coverage와 data frequency 각 각 분석의 4 가지 점수화 결과를 가지고 상관관계를 살펴본다. 이를 위해 아래〈표 5 〉와 같은 보 다 단순화된 점수 기준을 활용한다. 두 기준 간의 상관관계를 비교하면 총 16 개의 영역으로 점수 
화가 가능한데, 동 분석 단계에서는 이를 총 4가지 영역으로 단순화시킴으로써 data availability 에 대한 보다 전반적인 해석 결과를 도출할 수 있도록 한다. 우선 크게 poor/good 기준으로 단 순화하여, country coverage가 50\% 이하, 데이터 빈도수가 8개년 이하로 최저점을 기록하는 부 분을 A영역으로, 국가포함수준이 $50 \%$ 이상 $100 \%$ 이하, 데이터 빈도수가 8 개년 이상 16 개년 이 하로 최고점을 기록하는 부분을 $\mathrm{D}$ 영역으로 한다. 그리고 나머지 부분을 아래 표와 같이 $\mathrm{B}, \mathrm{C}$ 영 역으로 구분한다. 그리고 이러한 점수화 분류결과를 대상지표 전체차원 및 SDGs 17 개 목표별 차 원에서 각각 살펴봄으로써 어떠한 특징을 갖는지 각각 살펴봄으로써 data availability를 종합적 으로 평가한다.

〈표 5〉데이터 이용가능성(Data Availability) 점수화 기준

\begin{tabular}{|c|c|c|c|c|c|}
\hline & & \multicolumn{4}{|c|}{ Country Coverage (C.C) } \\
\hline & & very poor & quite poor & quite good & very good \\
\hline \multirow{4}{*}{$\begin{array}{c}\text { Data } \\
\text { Frequency } \\
\text { (D.F) }\end{array}$} & very poor & \multirow{2}{*}{\multicolumn{2}{|c|}{$\begin{array}{c}\text { A } \\
\text { C.C }(0<a \leq 50), D \cdot F(0<a \leq 8)\end{array}$}} & \multirow{2}{*}{\multicolumn{2}{|c|}{$\begin{array}{c}\text { C } \\
\text { C.C }(50<a \leq 100), \text { D.F(0<a } \leq 8)\end{array}$}} \\
\hline & quite poor & & & & \\
\hline & quite good & \multirow{2}{*}{\multicolumn{2}{|c|}{ C.C $(0<a \leq 50)$, D.F( $8<a \leq 16)$}} & \multirow{2}{*}{\multicolumn{2}{|c|}{ C.C $(50<a \leq 100)$, D.F $(8<a \leq 16)$}} \\
\hline & very good & & & & \\
\hline
\end{tabular}

출처: 저자 작성

아울러 아래〈그림 1〉은 이해의 편의를 위해 상기의 대상지표 선정에서부터 데이터 이용가능 성 종합분석에 이르는 일련의 분석과정을 도식화한 그림이다. 이러한 과정을 바탕으로 다음 장에 서 분석결과를 살펴본다.

〈그림 1〉SDGs 지표의 데이터 이용가능성 분석 과정 종합

\begin{tabular}{|c|c|c|c|c|}
\hline 대상지표 선정 & $\begin{array}{c}\text { 데이터 접근성 } \\
\text { (Data Accessibility) }\end{array}$ & \multicolumn{2}{|c|}{$\begin{array}{c}\text { 국가 포함 범위 } \\
\text { (Country Coverage) }\end{array}$} & $\begin{array}{l}\text { 데이터이용가능성 } \\
\text { (Data Availability) }\end{array}$ \\
\hline \multirow{3}{*}{$\begin{array}{l}\text { 전체 지표 230개 } \\
\text { (중복포함 241개) } \\
\text { 기준, Tier 1, Tier } \\
1 / 2 \text { 지표 정리 }\end{array}$} & \multirow{3}{*}{$\begin{array}{l}\text { 제시된 Data base source 기준, } \\
\text { 실제 접근 가능성 황인 } \\
\text { 제시된 데이터 방법론(data } \\
\text { methodology), 국제 기준(int'l } \\
\text { standard) 확립 유무, 데이터 베 } \\
\text { 이스 구축 유무 등에 대해 종합 } \\
\text { 고려 }\end{array}$} & \multicolumn{2}{|c|}{$\begin{array}{l}\text { 193개 UN 회원국 기준, 각 지표 } \\
\text { 별 포함되는 회원국 비증 도출 }\end{array}$} & \multirow{3}{*}{$\begin{array}{l}193 \text { UN 회원국 및 2000- } \\
\text { 2015년 기춘, 국고함범위 } \\
\text { 및 데이터빈도수 종합 려 }\end{array}$} \\
\hline & & & $\begin{array}{c}\text { 데이터 빈도수 } \\
\text { Data Frequency) }\end{array}$ & \\
\hline & & \multicolumn{2}{|c|}{$\begin{array}{l}\text { 2000년-2015년 기준, 각 지표별 } \\
\text { 데이터 이용가능 총 연수 }\end{array}$} & \\
\hline \multirow{3}{*}{\begin{tabular}{|c|}
$\begin{array}{c}\text { Tier1, } \\
\text { Tier1/2 }\end{array}$ \\
- 전체지표 \\
230개 \\
(중복포함 \\
241개) 대상
\end{tabular}} & 접근가능 데이터 & \multirow{3}{*}{$\begin{array}{l}\text { 국 } \\
\text { 가 } \\
\text { 포 } \\
\text { 함 } \\
\text { 범 } \\
\text { 위 }\end{array}$} & 데이터 빈도수 & $\begin{array}{l}\text { 데이텃 이용가능성 } \\
\text { 종합평가 }\end{array}$ \\
\hline & $\begin{array}{l}\text { - 제시된 Database source 기준 } \\
\text {-방법론(data methodology), } \\
\text {-둑제 기준(int'l standard) 환립 유무 } \\
\text {-데이터 베이스 구축 유무 밉 제시된 } \\
\text { Data base URL 실제 접근가능여부 }\end{array}$ & & \multirow[t]{2}{*}{$\begin{array}{l}\text { - } 193 \text { 개 UN회원국 대상 } \\
\text { - 2000년-2015년 대상 } \\
\text { - 각각 점수화 도출 } \\
\text { (very good, quite good, } \\
\text { quite poor, very poor) }\end{array}$} & \multirow{2}{*}{$\begin{array}{l}\text {-국가포함범위 및 데이터 } \\
\text { 빈도수 점수화 결과 종 } \\
\text { 합 비교 } \\
\text { (very good, quite good, } \\
\text { quite poor, very poor) }\end{array}$} \\
\hline & 접근 불가 데이터 & & & \\
\hline
\end{tabular}

출처: 저자 작성 


\section{SDGs 지표의 실제 데이터 이용가능성 (Data Availability)}

\section{SDGs Tier별 구성 분석}

〈표 6〉SDGs 전체 지표의 Tier별 구성

\begin{tabular}{|c|c|c|c|c|c|c|}
\hline SDG NO. & TIER1 & TIER2 & TIER3 & Tier $1 / 2$ & $\begin{array}{c}\text { Tier1/3, } \\
\text { Tier1/2/3, } \\
\text { untiered }\end{array}$ & 합겨 \\
\hline 1 & 3 & 4 & 4 & 0 & 1 & 12 \\
\hline 2 & 7 & 2 & 5 & 0 & 0 & 14 \\
\hline 3 & 15 & 7 & 3 & 0 & 1 & 26 \\
\hline 4 & 3 & 4 & 2 & 1 & 1 & 11 \\
\hline 5 & 3 & 4 & 6 & 1 & 0 & 14 \\
\hline 6 & 6 & 0 & 5 & 0 & 0 & 11 \\
\hline 7 & 4 & 0 & 2 & 0 & 0 & 6 \\
\hline 8 & 10 & 6 & 1 & 0 & 0 & 17 \\
\hline 9 & 8 & 1 & 3 & 0 & 0 & 12 \\
\hline 10 & 4 & 0 & 5 & 1 & 1 & 11 \\
\hline 11 & 2 & 7 & 6 & 0 & 0 & 15 \\
\hline 12 & 1 & 3 & 8 & 0 & 1 & 13 \\
\hline 13 & 0 & 2 & 4 & 0 & 1 & 7 \\
\hline 14 & 2 & 0 & 8 & 0 & 0 & 10 \\
\hline 15 & $6^{*}$ & 1 & 5 & 0 & 2 & 14 \\
\hline 16 & 9 & 7 & 6 & 0 & 1 & 23 \\
\hline 17 & 15 & 2 & 5 & 0 & 3 & 25 \\
\hline 합 계 & 98 & 50 & 78 & 3 & 12 & 241 \\
\hline $\begin{array}{c}\text { 중복지표 } \\
\text { 제외시 }\end{array}$ & 96 & 44 & 76 & 3 & 11 & 230 \\
\hline
\end{tabular}

* IAEG-SDGs (2016) 보고서 상에서 15.c.1 (Proportion of traded wildlife that was poached or illicitly trafficked) 지표 의 'Reviesed Tier(by Secretariat)' 란이 공백으로 되어 있음. 하지만 동 지표는 Tier1에 해당하는15.7.1과 중복(repeat of 15.7.1)된다고 표시되어 있다는 점에서 동 15.c.1 지표 역시도 Tier1로 계산하였음을 밝힌다.

출처: IAEG-SDGs (2016) 자료 바탕으로 저자 작성 
상기 〈표 6〉와 같이 SDGs 전체 지표의 개수는 중복지표를 포함하여 총 241개이며, 아래〈표 7)와 같이 11 개의 중복지표를 제외한 개수는 230 개이다. 먼저 11 개의 중복지표 현황을 살펴보 면, 가장 많은 중복지표를 가지고 있는 Tier2는 총 4개의 지표가 각각 2 3번씩 중복적으로 사용 되고 있으며, 그 뒤를 이은 Tier1,3은 각각 총 2 개의 지표들이 2 번씩 중복되고 있다. 그리고 마지막으로 Tier $1 / 3$ 은 1 개의 지표가 2 번 중복되어 사용된다. 각 Tier별 지표의 개수를 비교해보 았을 때, Tier1의 개수가 96개(중복제외)로, 전체 대비 약 $42 \%$ 를 차지하며, 반대로 Tier3의 개수 는 76개(중복제외)로 전체 대비 약 $33 \%$ 로 Tier1 다음으로 많은 비중을 차지하고 있다.

〈표 7〉SDGs 각 중복 지표 현황3)

\begin{tabular}{|c|c|c|c|c|}
\hline 구분 & 최초 지표 & 중복 지표 1 & 중복 지표 2 & 지표 개수 \\
\hline \multirow{2}{*}{ Tier1 } & 10.6 .1 & 16.8 .1 & & 2 \\
\hline & 15.7 .1 & 15.c. 1 & & 2 \\
\hline \multirow{4}{*}{ Tier2 } & 1.5.1 & 13.1 .2 & 11.5 .1 & 3 \\
\hline & 1.5 .3 & 11.b.2 & 13.1 .1 & 3 \\
\hline & 8.4 .1 & 12.2 .1 & & 2 \\
\hline & 8.4 .2 & 12.2 .2 & & 2 \\
\hline \multirow{2}{*}{ Tier3 } & 7.a.1 & 13.a. 1 & & 2 \\
\hline & 10.3.1 & 16.b. 1 & & 2 \\
\hline Tier1/3 & 15.a.1 & 15.b.1 & & 2 \\
\hline 소계 & 9 & 9 & 2 & 20 \\
\hline \multicolumn{2}{|c|}{ 총 중복 지표 개수 } & \multicolumn{2}{|c|}{11} & \\
\hline
\end{tabular}

출처: IAEG-SDGs (2016) 자료 바탕으로 저자 작성

아래〈표 8〉은 SDGs 17개 목표별로 각각 Tier1의 구성이 어떠한지를 나타낸 표이다. 우선 각 목표별 전체 지표 중 Tier1 비중이 가장 높은 지표는 목표7(에너지)와 목표9(인프라·산업화)로,

3) SDGs 230개 지표는 중복 counting 된 지표를 제외한 개수이며, 중복지표 9개를 중복 counting한 전체 지표 개수는 241개가 된다. 해당 중복지표 9개는 다음과 같다; (1) 10.6.1 Proportion of members and voting rights of developing countries in international organizations (16.8.1과 중복), (2) 15.7.1 Proportion of traded wildlife that was poached or illicitly trafficked (15.c.1과 중복), (3) 1.5.1 Number of deaths, missing and persons affected by disaster per 100,000 people (13.1.2, 11.5.1과 중복), (4) 1.5.3 Number of countries with national and local disaster risk reduction strategies (11.b.2, 13.1.1과 중복), (5) 8.4.1 Material footprint (MF) and MF per capita, per GDP (12.2.1과 중복), (6) 8.4.2 Domestic material consumption (DMC) and DMC per capita, per GDP (12.2.2와 중복), (7) 7.a.1 Mobilized amount of United States dollars per year starting in 2020 accountable towards the $\$ 100$ billion commitment (13.a.1과 중복), (8) 10.3.1 Proportion of the population reporting having personally felt discriminated against or harassed within the previous 12 months on the basis of a ground of discrimination prohibited under international human rights law (16.b.1과 중복), (9) 15.a.1 Official development assistance and public expenditure on conservation and sustainable use of biodiversity and ecosystems (15.b.1과 중복) (출처: IAEG-SDGs(2016.03) 에서 저자 발췌 인용) 
각 목표 내 전체 지표 개수 대비 $66.7 \%$ 를 차지하고 있다. 그 외에도 각 목표별 전체 지표 중 Tier1 지표 비중이 절반 이상을 차지하는 목표로는 목표17(이행수단·파트너십), 목표8(고용·일자 리), 목표3(보건복지), 목표6(식수위생), 목표2(식량안보 및 농업) 등 총 7개이다. 반면 목표13(기 후변화)는 Tier1 지표가 전무하며 목표12(소비와 생산) 역시도 해당 목표 내 Tier1 지표가 1개 (7.7\%) 밖에 없어 매우 낮은 비중을 차지하고 있다.

〈표 8〉SDGs 목표별 Tier1 구성 세부 분석표

\begin{tabular}{|c|c|c|c|c|}
\hline 목표 번호 & $\begin{array}{c}\text { 목표별 } \\
\text { 전체지표 } \\
\text { 개수(a) }\end{array}$ & Tier1 개수 & $\begin{array}{c}\text { 목표별 } \\
\text { 전체지표기준(a), } \\
\text { Tier1 비중 } \\
\text { (\%) }\end{array}$ & $\begin{array}{c}\text { 전체 Tier1기준(b), } \\
\text { 목표별Tier1비중 (\%) }\end{array}$ \\
\hline 1 (빈곤종식) & 12 & 3 & 25 & 3.1 \\
\hline 2 (식량안보, 농업) & 14 & 7 & 50 & 7.1 \\
\hline 3 (보건 복지) & 26 & 15 & 57.7 & 15.3 \\
\hline 4 (교육) & 11 & 3 & 27.3 & 3.1 \\
\hline 5 (성평등) & 14 & 3 & 21.4 & 3.1 \\
\hline 6 (식수위생) & 11 & 6 & 54.5 & 6.1 \\
\hline 7 (에너지) & 6 & 4 & 66.7 & 4.1 \\
\hline 8 (고용 일자리) & 17 & 10 & 58.8 & 10.2 \\
\hline 9 (인프라 산업화) & 12 & 8 & 66.7 & 8.2 \\
\hline 10 (불평등) & 11 & 4 & 36.4 & 4.1 \\
\hline 11 (도시) & 15 & 2 & 13.3 & 2.0 \\
\hline 12 (소비와 생산) & 13 & 1 & 7.7 & 1.0 \\
\hline 13 (기후변화) & 7 & 0 & 0 & 0 \\
\hline 14 (해양자원) & 10 & 2 & 20 & 2.0 \\
\hline 15 (생물다양성) & 14 & 6 & 42.9 & 6.1 \\
\hline 16 (평화제도) & 23 & 9 & 39.1 & 9.2 \\
\hline 17 (이행수단, 파트너십) & 25 & 15 & 60 & 15.3 \\
\hline 합 계 & 241 & $98(b)$ & 40.7 & 100 \\
\hline
\end{tabular}

출처: 저자 작성

또한 SDGs Tier1 전체 지표 98개가 각 목표별로 어떻게 구성되어 있는지를 살펴보면, 목표3 (보건복지)과 목표17(이행수단·파트너십)이 전체 대비 $15.3 \%$ 로 가장 높은 비중을 보이고 있으며, 목표8(고용-일자리)이 $10.2 \%$ 로 높은 비중을 차지하고 있다. 반대로 목표13(기후변화)는 Tier1 지 표 자체가 없는 관계로 해당 비중은 $0 \%$ 를 보이며, 목표 12 (소비와 생산) 역시 1 개 Tier1 지표를 갖고 있어 전체 98 개 지표 대비 $1 \%$ 의 비중을 차지하고 있다. 
위의 표를 바탕으로 이를 종합해보았을 때 목표3(보건복지), 목표8(고용·일자리), 목표17(이행 수단·파트너십)이 각 목표별 내부적으로도, Tier1 98개 지표 전체적으로도 Tier1의 비중을 가장 많이 가지고 있어 비교적 지표의 안정성을 높게 가지고 있다고 할 수 있다. 반면 목표12(소비와

제 I 장

제 II 장 우 낮아 지표의 안정성이 취약하다 할 수 있을 것이다. 특히 기후변화의 경우, '경제성장, 사회발 전, 환경보호라는 SDGs 3대 축을 구성하는 환경관련 독립목표임에도 불구하고 Tier1 지표가 전 무하다는 점에서 사실상 실질적인 지표 이행 가능성에 있어 17 개 지표 중 가장 큰 한계를 노정한 다고 할 수 있다.

\section{Data Accessibility 분석}

동 연구에서 분석 대상이 되는 지표인 Tier1과 Tier1/2지표 총 101개에 대해 1차적으로 $\mathrm{IAEG}-\mathrm{SDGs}(2016.03)$ 보고서 및 $\mathrm{CGD}(2016)$ 분석자료를 가지고 실제 SDGs 지표가 IAEGSDGs 보고서상에 제시된 data base에서 얻을 수 있는지를 살펴보고, 그렇지 않다면 이를 대체 할 metadata 또는 $\mathrm{CGD}(2016)$ 분석자료 상에 제시하고 있는 proxy URL로 원하는 데이터를 얻 을 수 있는지를 살펴본다.

우선 IAEG-SDGs(2016.03) 보고서 상에 각 지표별로 제시되어 있는 정보에 기반하여 (1) 방법 론(methodology) 존재여부(기 테스트 여부 포함), (2) 동 방법론에 대한 국제적 합의(international agreeement) 여부, (3) 메타데이터(meta data) 보유 여부, (4) 데이터베이스(database) 보유 여부 등 4가지 기준으로 데이터 접근성(data accessibility)을 종합적으로 살펴보았다. 여기서 'data accessibility'는 위의 네 가지 기준을 모두 충족하는지를 살펴보는 것이며, 이 중 한 가지 요소라 도 미충족될 경우 현재로서는 해당 지표에 대한 명확한 기준에 따른 데이터 확보가 어려운 지표 라고 해석한다.

아래〈표 9〉는 이러한 4가지 기준에 의거하여 접근성이 사실상 제한되어 있는 지표들을 보여 준다. 동 표의 해석과 관련하여, 방법론(methodology)에서의 ' $\triangle$ '는 방법론은 존재하나 아직 테 스트가 되지 않은(“There is a suggested methodology, but it has not been tested” 해당) 상태를 말하며, 데이터베이스(database)상에서의 ' $\triangle$ '는 지표 상의 분석 대상 중 일부에 대해서만 데이터베이스가 제시된 경우를 말한다. 


\begin{tabular}{|c|c|c|c|c|c|c|c|c|c|c|c|c|c|c|}
\hline 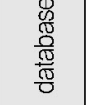 & $x$ & $\times$ & $\times$ & 0 & $\times$ & $\triangleleft$ & $\triangleleft$ & 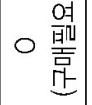 & 0 & $\times$ & $x$ & $\times$ & $\times$ & 0 \\
\hline$\frac{\mathbb{D}}{\frac{\pi}{0}} \frac{\frac{\pi}{\pi}}{\frac{\pi}{0}}$ & $\times$ & $\times$ & $\times$ & 0 & 0 & $\times$ & $\times$ & 0 & 0 & $x$ & 0 & 0 & 0 & 0 \\
\hline 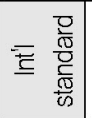 & 0 & 0 & 0 & $\times$ & 0 & 0 & 0 & 0 & 0 & $\times$ & $\circ$ & $\times$ & 0 & $\times$ \\
\hline 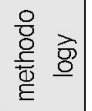 & 0 & 0 & 0 & 0 & 0 & 0 & 0 & 0 & $\triangleleft$ & $\times$ & $\circ$ & 0 & 0 & 0 \\
\hline $\overrightarrow{\stackrel{\vec{\vartheta}}{丂}}$ & I & 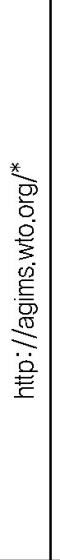 & 1 & 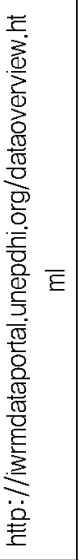 & 1 & 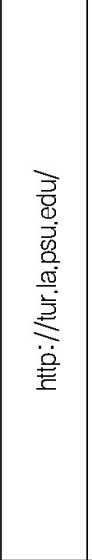 & 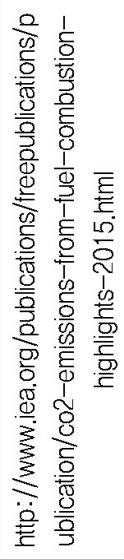 & 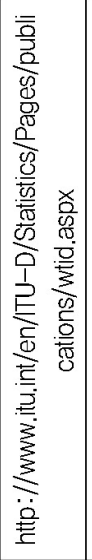 & 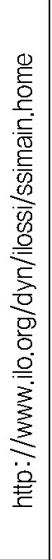 & 1 & 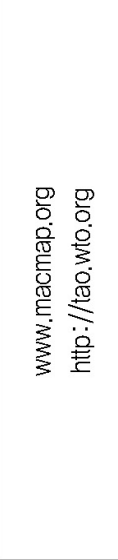 & 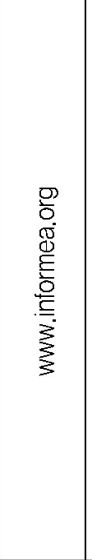 & 1 & 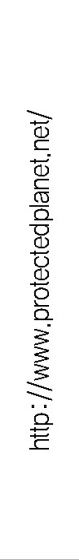 \\
\hline 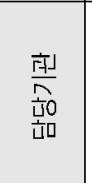 & 운 & 얀 & \begin{tabular}{l}
\multicolumn{1}{c}{} \\
㟔 \\
$\vdots$ \\
$\Xi$
\end{tabular} & 岀 & 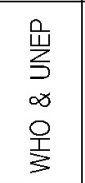 & $\stackrel{\varrho}{=}$ & 总舐 & 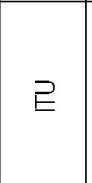 & $\stackrel{\rho}{\underline{ }}$ & $\begin{array}{l}\stackrel{ }{\stackrel{?}{E}} \\
\text { 을 }\end{array}$ & 产高 & 岀 & $\frac{9}{4}$ & 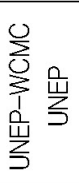 \\
\hline 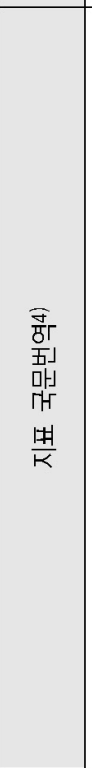 & 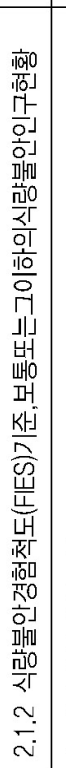 & 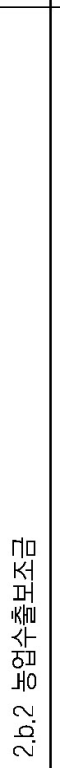 & 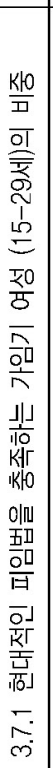 & 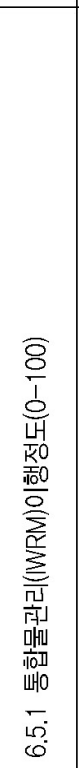 & 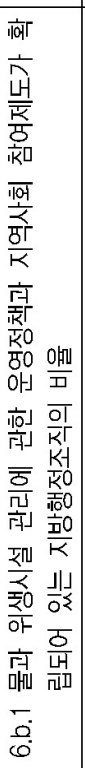 & 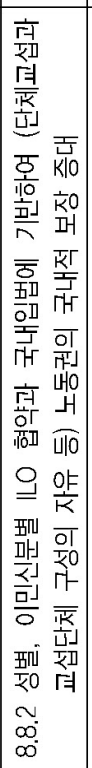 & 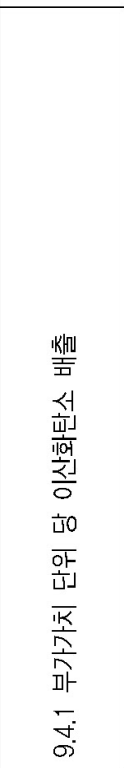 & 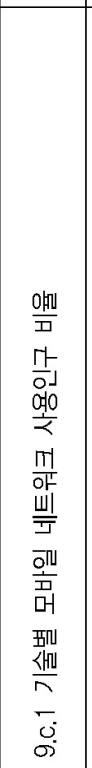 & 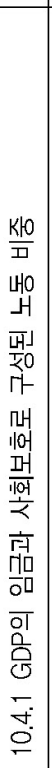 & 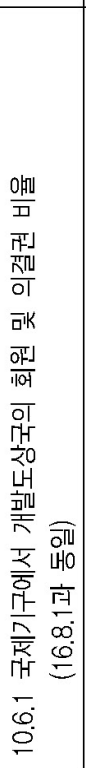 & 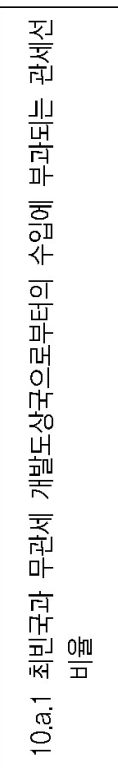 & 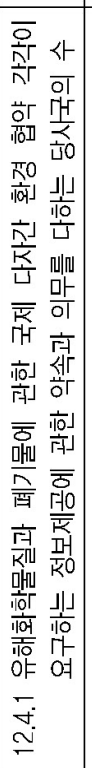 & 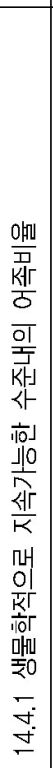 & 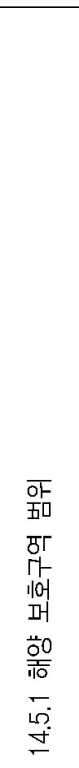 \\
\hline
\end{tabular}




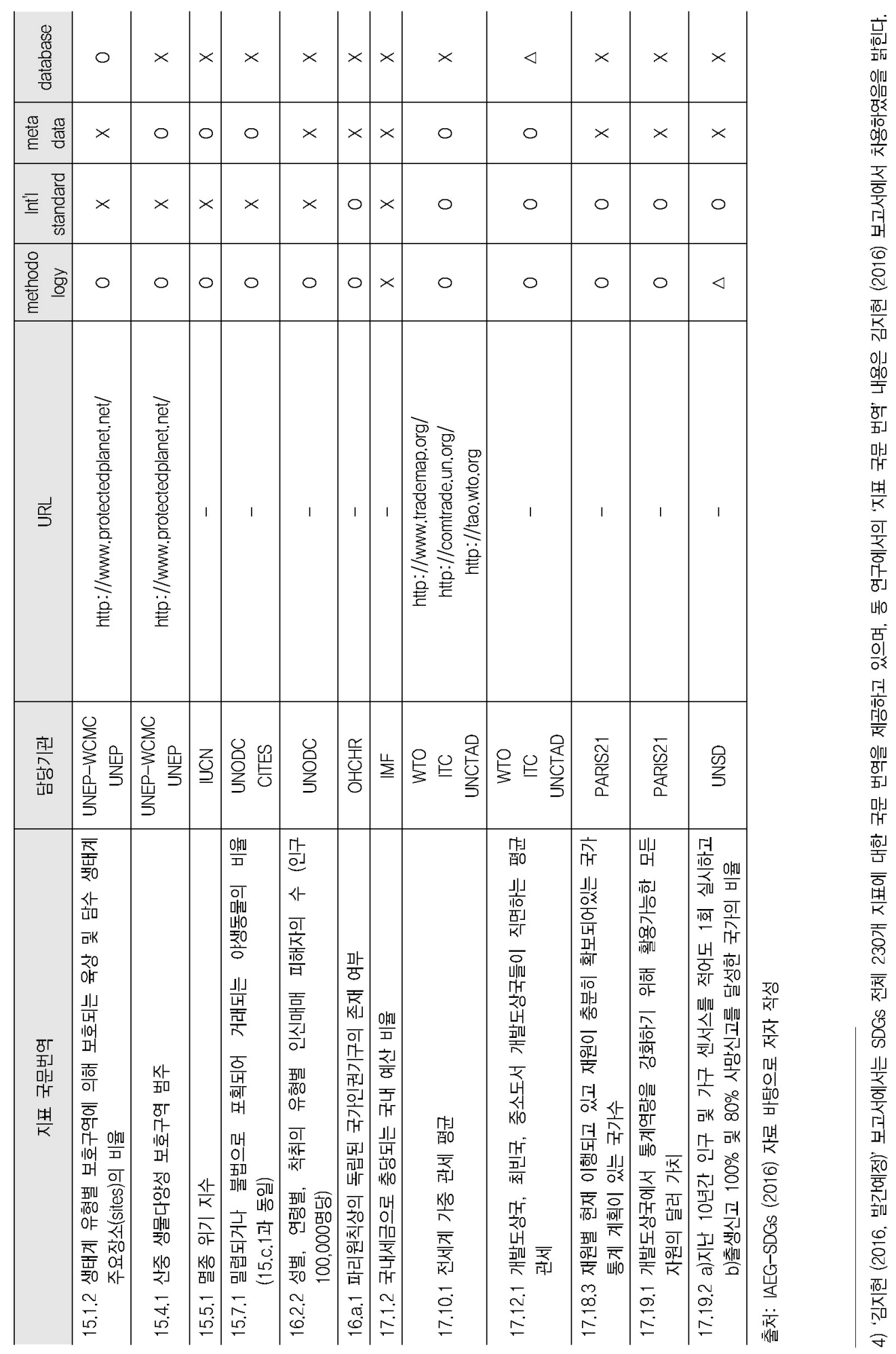

제 I 장

제 II 장

섹

터

제 III장 
위의 표에서 보는 바와 같이, 중복되는 두 개 지표5)를 포함하여 총 28 개 지표를 살펴보면 28 개 지표 중 3 개 지표를 제외한 나머지 지표들이 방법론을 이미 가지고 있으며, 각 지표의 개념 및 범위 등에 대한 국제적 합의가 이루어진 지표는 총 16 개이다. 이를 통해 총 14 개의 지표가 이 미 방법론 및 지표 개념에 대한 국제적 합의 모두가 확보되어 있으며, 이는 Tier1 지표 전체적으 로 방법론 및 국제적 합의 부분에 대한 완성도가 비교적 높다고 평가할 수 있다. 하지만 반대로 아직 Tier1지표임에도 불구하고 각 지표의 개념 및 범위에 대한 국제적 합의가 이루어지지 않은 지표가 12 개나 존재한다는 것은, 지표 해석의 모호함을 해소하고 보다 명확한 해석과 활용을 위 해서 지표 개발 및 보완이 시급함을 의미하기도 한다.

또한 28개 대상 지표 중 지표 내용에 대한 데이터를 완전히 얻을 수 있는 지표는 6 개에 불과 하고 지표에 대한 부분적인 정보를 얻을 수 있는 지표 역시 3개에 그친다. 이로 인해 나머지 19 개 지표에 대한 데이터베이스가 아직 마련되지 못한 상태이다. 하지만 각 지표의 데이터 수준을 내려 raw data에 가까운 자료를 얻으면 좋지만 사실상 국제개발분야에서의 데이터는 목적에 맞 추어 재가공된 메타데이터 활용이 불가피하다. 따라서 현재 데이터베이스가 마련되지 않은 지표 에 대해 메타데이터를 통해 모델링된 데이터를 얻을 수 있다면 데이터베이스가 부재함에 따른 한 계를 보완할 수 있을 것이다. 그러나 표에서 볼 수 있는 바와 같이 이러한 보완역할을 하는 지표, 즉 데이터베이스가 부재하나 메타데이터가 존재하는 지표는 9 개이며, 두 데이터 모두가 부재한 지표는 11 개에 이르는 실정이다.

이렇게 data accessibility에 해당하는 네 가지 기준에 따라 Tier1, Tier1/2지표를 살펴보면 전체 101 개 지표 중 data accessibility가 보장되는 지표는 총 73 개, 그렇지 않은 지표는 총 28 개로 도출된다. 아래 〈그림 2)는 SDGs 각 목표별 지표들의 data accessibility이 어떻게 구성되 어 있는지를 보여주고 있다.

5) 중복되는 두 지표는 다음과 같다. (1)10.6.1 Proportion of members and voting rights of developing countries in international organizations (16.8.1 과 중복), (2)15.7.1 Proportion of traded wildlife that was poached or illicitly trafficked(15.c.1과 중복) (출처: IAEG-SDGs(2016)에서 저자 발췌 인용) 
〈그림 2〉 각 목표별 Tier1, Tier1/2 지표의 데이터 접근성 구성

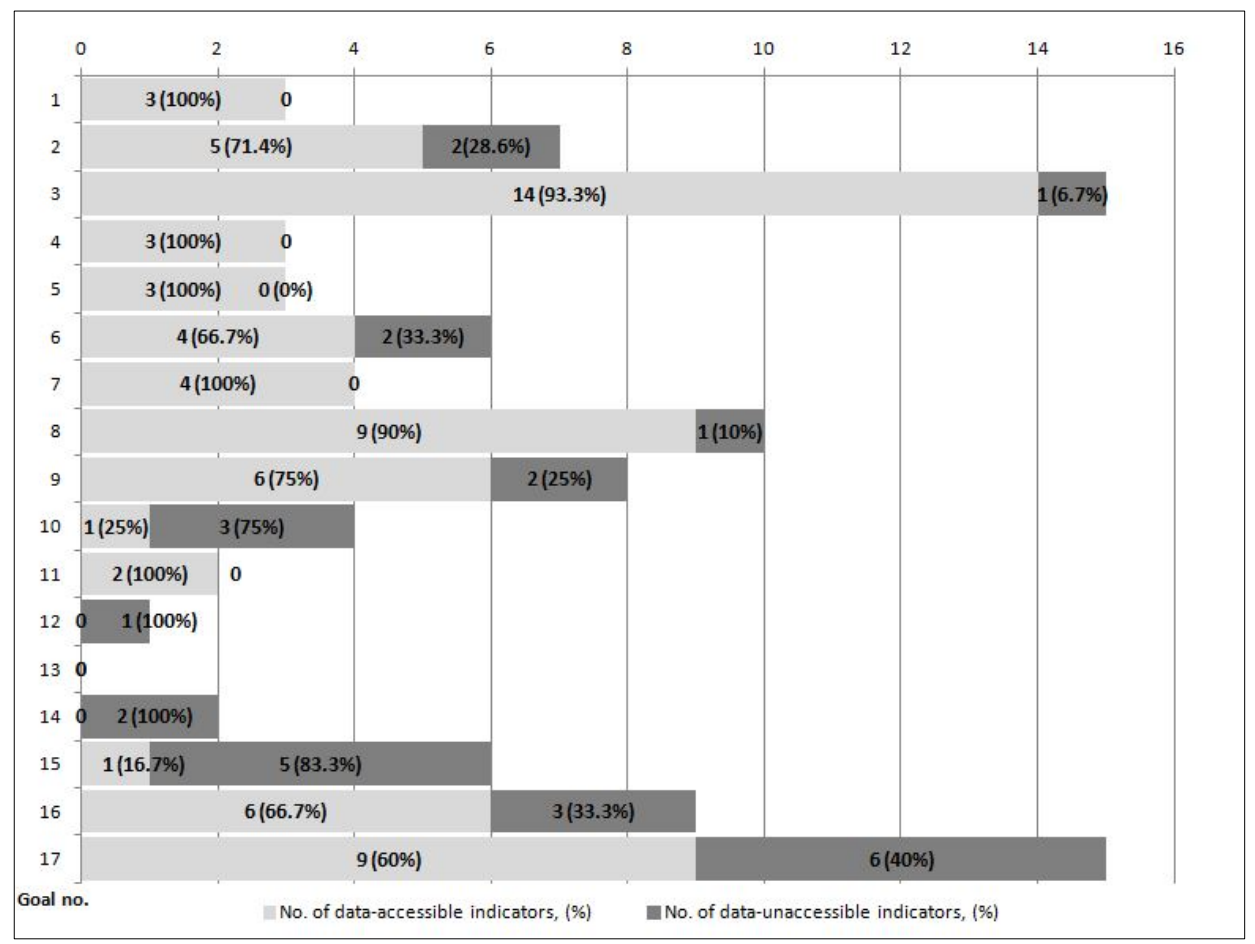

출처: 저자 작성

위의 그림에서와 같이, 각 목표별 Tier1, Tier $1 / 2$ 구성지표를 볼 때, 목표1(빈곤종식), 목표4 (교육), 목표5(성평등), 목표7(에너지), 목표11(도시) 등 총 5 개 목표의 모든 대상지표가 data accessibility가 보장되어 있다(100\%). 또한 목표3(보건복지), 목표8(고용·일자리) 등 두 개의 목 표도 각각 $90 \%$ 이상의 높은 data accessibility를 가지고 있음을 알 수 있다.

하지만 반대로 구성 Tier1, Tier1/2 지표의 data accessibility가 현격히 낮아 지표의 측정 및 모니터링이 어려운 목표들이 있는데, 그 대표적인 것이 목표 10 (불평등), 목표 12 (소비와 생산), 목 표13(기후변화), 목표14(해양자원), 목표15(생물다양성)이다. 이 중에서 목표12와 목표14는 모든 대상지표들이 data accessibility가 제한되어 있어 현재로서는 이용가능한 데이터가 없는 상태이 며, 목표10과 목표15는 데이터 접근이 가능한 지표가 각각 1 개로 매우 낮은 data accessibility 를 보이고 있다.

이러한 전반적인 Tier1, Tier1/2 지표에 대한 분석을 바탕으로, 동 연구에서의 country coverage 및 data frequency 분석의 대상지표로는 데이터 확보가 불가능한 상기 28개 지표를 제외한 나머지 73 개 지표가 된다. 특히 각 목표별 차원에서 보면, 목표 12 (소비와 생산), 목표 13 (기후변화), 목표14(해양자원)은 데이터 접근이 가능한 지표가 없기 때문에 이를 제외한 나머지 
14 개 목표가 동 연구에서의 country coverage 및 data frequency 분석 대상이 된다.

\section{Country Coverage 분석}

국가포함수준(Country Coverage)이란 총 UN 회원 193개국 중 2000년 2015년 사이에 한 해라도 데이터가 제공되는 국가의 비중(\%)으로 정의한다. 데이터 이용이 가능한 73 개 지표 각각 의 countrycoverage를 살펴보기 위해 최소값 $0 \%$ 에서 최대값 $100 \%$ 으로 하여 각 총 4 가지 점수 기준으로 분류하여 분석을 시도하였다.

아래〈그림 3〉은 Tier1과 Tier1/2 지표 총 73 개 각각에 대해 UN 회원국 193 개 국가들에 대 한 country coverage를 $25 \%$ 단위로 나누어 점수화한 그래프이다. 아래 그림에서 보는 바와 같 이 43 개 지표(58.9\%)와 20개 지표(27.4\%)가 각각 very good, quite good 점수를 얻음에 따라 절반 이상의 국가에 대해 2000년부터 16 개년 동안 적어도 1 개년 이상의 자료를 얻을 수 있음을 알 수 있다. 이는 전체 73 개 지표 중 10개를 제외한 대다수의 지표가 country coverage에 대해 서는 비교적 안정된 모습을 보인다고 해석할 수 있다. 특히 country coverage가 99\%이상을 보이 는 지표가 9개6)에 이르며, 그 중 지표 17.8.1(인터넷 사용 인구 비율)은 $100 \%$ 의 country coverage 를 보이고 있다. ${ }^{7)}$

〈그림 3〉대상 73개 지표의 Country Coverage 점수화

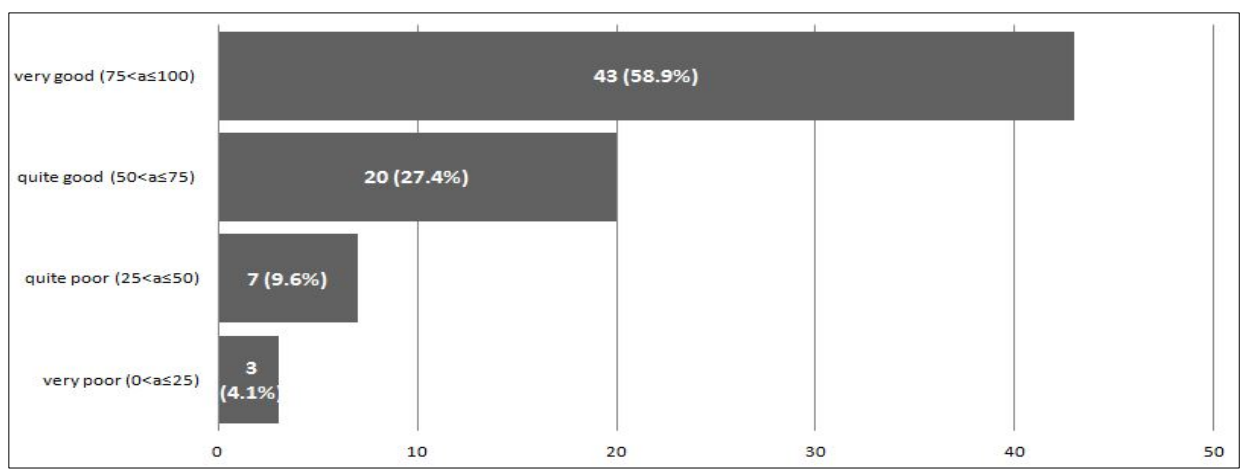

출처: 저자 작성

6) 해당 9 개 지표는 다음과 같다. (1) 3.2.1. Under-five mortality rate (99\%), (2) 3.2.2. National mortality rate (99\%), (3) 3.3.2 Tuberculosis incidence per 1,000 population (99\%), (4) 3.3.5 Number of people requiring interventions against neglected tropical diseases (99\%), (5) 5.5.1 Proportion of seats held by women in national parliaments and local governments (99\%), (6) 7.1.1. Proportion of population with access to electricity (99\%), (7) 7.1.2. Proportion of population with primary reliance on clean fuels and technology (99\%), (8) 16.1.1 Number of victims of intentional homicide per 100,000 population, by sex and age, (9) 17.8.1 Proportion of individuals using the Internet (100\%) (출처: IAEG-SDGs(2016.03)에서 저자 발췌 인용)

7) Tier1, Tier1/2 지표별 country coverage 전체 비중 및 점수는 동 연구의 ‘별첨] 73개 지표 전체 총괄표를 참조하기 바란다. 
반면 country coverage 비중이 25\%이하로 very poor 점수를 얻은 지표는 4.a.1 (a)전기, (b) 수업용 인터넷, (c)수업용 컴퓨터, (d)장애학생을 위한 설비 및 교재, (기초식수, (f)성별로 분리 되어 있는 기초위생시설, (g)기초손씻기 시설(WASH지표 정의에 의거)에 대한 접근성을 가지고 있는 학교 비율), 지표 4.c.1(국별기준에 부합하는 최소수준의 체계적인 자격전 및 재교육을 받은 (a)유치원, (b)초등학교, (C)중등학교, (d)고등학교 교사비율)와 5.3.2 (15-49세 소녀 및 여성 중 여 성 성기절제를 받은 인구의 연령별 비중) 등 총 3 개로, 각각 $21 \%, 16 \%, 15 \%$ 의 낮은 비중을 보 이고 있다.

아래 〈그림 4)는 각 목표별로 country coverage 점수화 구성이 어떠한지를 나타내고 있다. 목 표별로 보면, 목표11(도시)에 해당하는 11.1.1(빈민가, 무허가 또는 적절치 않은 주거지에서 거주 하는 도시 인구 비율), 11.6.2(도시내 PM2.5 및 PM10 등으로 표기되는 연중 미세먼지 평균 수 준) 두 지표 모두의 country coverage가 각각 $42 \%, 47 \%$ 로 quite poor에 해당하며, 이를 제외한 나머지 목표의 경우 quite good과 very good의 비중이 비교적 꽤 높다고 할 수 있다. 그 중에서 는 목표6(식수위생)과 목표7(에너지), 목표15(생물다양성)는 해당지표 전체가 $75 \%$ 이상의 높은 country coverage를 보이고 있으며, 목표2(식량안보·농업), 목표3(보건복지), 목표9(인프라·산업 화), 목표17(이행수단파트너십) 역시 모든 지표가 50\% 이상의 높은 country coverage를 보인다.

〈그림 4〉목표별 Country coverage 점수화 구성 현황

\begin{tabular}{|r|r|r|r|r|r|r|r|}
\hline & & & \\
\hline
\end{tabular}

출처: 저자 작성 
특히 목표3(보건복지)의 경우, Tier1의 개수가 전체 목표 중 15 개로 가장 많은 동시에 3.7.1 (현대적 피임법을 충족하는 가임기 여성(15-29세)의 비중)을 제외한 14 개 지표 모두가 data accessibility를 확보하고 있다. 또한 동 목표의 country coverage가 very good이 11개, quite $\operatorname{good}$ 이 3 개로 구성되어 있어, 14 개 지표 전체가 대상 국가들의 $50 \%$ 이상을 커버하고 있다는 점 에서 비교적 안정적으로 국별 데이터를 획득할 수 있다. 특히 Tier1, Tier $1 / 2$ 지표 전체 기준으 로 볼 때, country coverage가 99\% 이상인 총 9개 지표 중 3.2.1(5세 이하 아동 사망률), 3.2.2(신생아 사망률), 3.3.2(인구 1,000 명당 결핵 발생률) 등 3 개 지표가 목표3에 해당한다는 점에서 다른 목표들에 비해 country coverage가 매우 안정적이라고 평가할 수 있다.

이렇듯 상기의 Tier1, Tier1/2 지표 전체 및 각 목표별 차원에서 country coverage를 분석해 보았을 때, 두 분석기준 모두에서 비교적 안정적인 결과를 도출할 수 있다. 즉, 전체적 차원에서 보았을 때, $50 \%$ 이상의 country coverage를 갖는 지표의 개수가 총 63개(86.3\%)로 높은 비중 을 차지하고 있는 동시에 목표차원에서 볼 때에도 data accessibility가 결여된 목표12(소비와 생 산), 목표13(기후변화), 목표14(해양자원) 및 country coverage가 50\% 미만인 지표로만 구성된 목표11(도시) 등 4개의 목표를 제외 시, 나머지에서는 전반적으로 country coverage가 안정적으로 구성되어 있다고 할 수 있다.

\section{Data Frequency 분석}

데이터 빈도수(Data Frequency)란, 각 지표별로 한 해라도 데이터를 제공한 193개 UN 회원 국들의 평균 데이터 제공 연수로 정의한다. 상기의 country coverage 자체에서도 2000년에서 2015 년까지 총 16 개년 동안 1 년이라도 데이터를 제공한 국가의 전체 비중이라고 정의한 바와 같 이, Data frequency 역시도 이러한 country coverage 기준을 통해 걸러진 대상국가들의 평균 데이터 제공 연수를 나타낸다. 데이터 이용이 가능한 73 개 지표 각각의 data frequency를 살펴 보기 위해 동 단계에서는 최소값 0 에서 최대값 16 으로 하여 각 총 4 가지 점수기준으로 분류하여 분석을 시도하였다.

아래〈그림 5〉는 Tier1과 Tier1/2 지표 총 73개 각각에 대해 2000년에서 2015년까지 총 16 개년 동안 한 해라도 데이터를 제공한 193 개 UN 회원국에 대한 data frequency를 $25 \%$ 단위로 나누어 점수화한 그래프이다. 아래 그림에서 보는 바와 같이 대상국가들의 평균 데이터 제공연수 가 12 개년 이상인 지표는 31 개로 전체 대비 $42.5 \%$ 라는 높은 비중을 차지하고 있다. 특히 data frequency가 평균 15.9 년 이상, 즉 16 개년 최대치에 근접한 지표가 5 개8)에 이르며, 그 중

8) 해당 5개 지표는 다음과 같다. (1) 2.1.1 Prevalence of undernourishment(15.96), (2) 3.2.1 Under-five mortality 
8.2.1(취업인구 1 인당 실질 $\mathrm{GDP}$ 성장률)은 평균 16년이라는 최대치를 보이고 있으며, 15.1.1(총 육지 면적 중 산림 면적의 비율) 역시 평균 15.99 라는 최대값에 매우 근사한 수치를 보이고 있다. $\left.{ }^{9}\right)$

〈그림 5〉대상 73개 지표의 Data Frequency 점수화

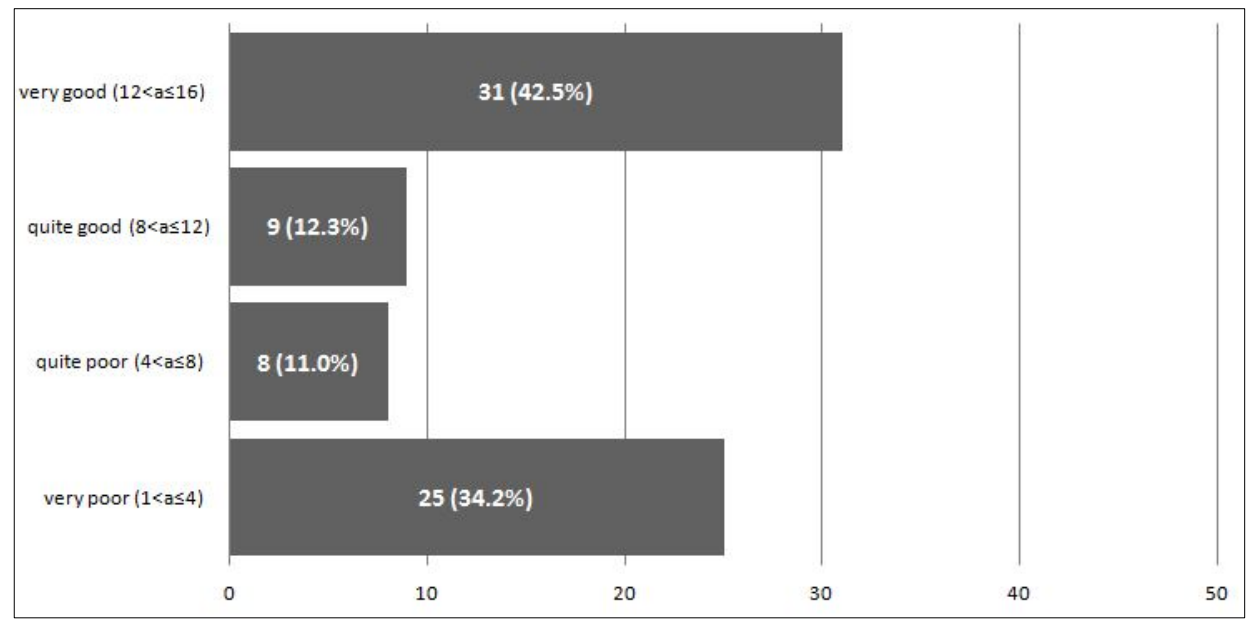

출처: 저자 작성

반면 data frequency 값이 평균 4년 이하로 very poor 점수를 얻은 지표 역시도 총 25 개로 전체 대비 $34.2 \%$ 라는 비교적 높은 수치를 보이고 있다. 특히 이 중에서도 평균 데이터 제공 연수 가 1 년 이하인 지표가 전체 very poor 25 개 지표 중 12 개10)나 차지한다는 점에서 Tier1, Tier1/2 지표의 2000년 이후로의 data frequency는 사실상 불안정하다고 할 수 있다.

rate(15.93), (3) 3.2.2 Neonatal mortality rate(15.92), (4) 8.2.1 Annual growth rate of real GDP per employed person(16), (5) 15.1.1 Forest area as a proportion of total land area(15.99)

9) Tier1, Tier1/2 지표별 data frequency 전체 비중 및 점수는 동 연구의 '별첨] 73개 지표 전체 총괄표를 참조하기 바람.

10) 해당 12개 지표는 다음과 같다. (1) 3.3.5 Number of people requiring interventions against neglected tropical diseases(1), (2) 3.5.2 Harmful use of alcohol, defined according to the national context as alcohol per capita consumption (aged 15 years and older) within a calendar year in litres of pure alcohol(1), (3) 3.6.1 Death rate due to road traffic injuries(1), (4) 3.9.1 Mortality rate attributed to household and ambient air pollution(1), (5) 5.3.1 Proportion of women aged 20-24 years who were married or in a union before age 15 and before age 18(1), (6) 5.3.2 Proportion of girls and women aged 15-49 years who have undergone female genital mutilation/cutting, by age(1), (7) 7.1.2 Proportion of population with primary reliance on clean fuels and technology(1), (8) 8.7.1 Proportion and number of children aged 5-17years engaged in child labour, by sex and age(1), (9) 10.1.1 Growth rates of household expenditure or income per capita among the bottom 40 per cent of the population and the total population(1), (10) 11.6.2 Annual mean levels of fine particulate matter (e.g. PM2.5 and PM10) in cities (population weighted)(1), (11) 16.2.1 Proportion of children aged 1-17 years who experienced any physical punishment and/or psychological aggression by caregivers in the past month(1), (12) 16.9.1 Proportion of children under 5 years of age whose births have been registered with a civil authority, by age(1) (출처: IAEG-SDGs (2016)에서 저자 발췌 인용) 
〈그림 6〉목표별 Data Frequency 점수화 구성 현황

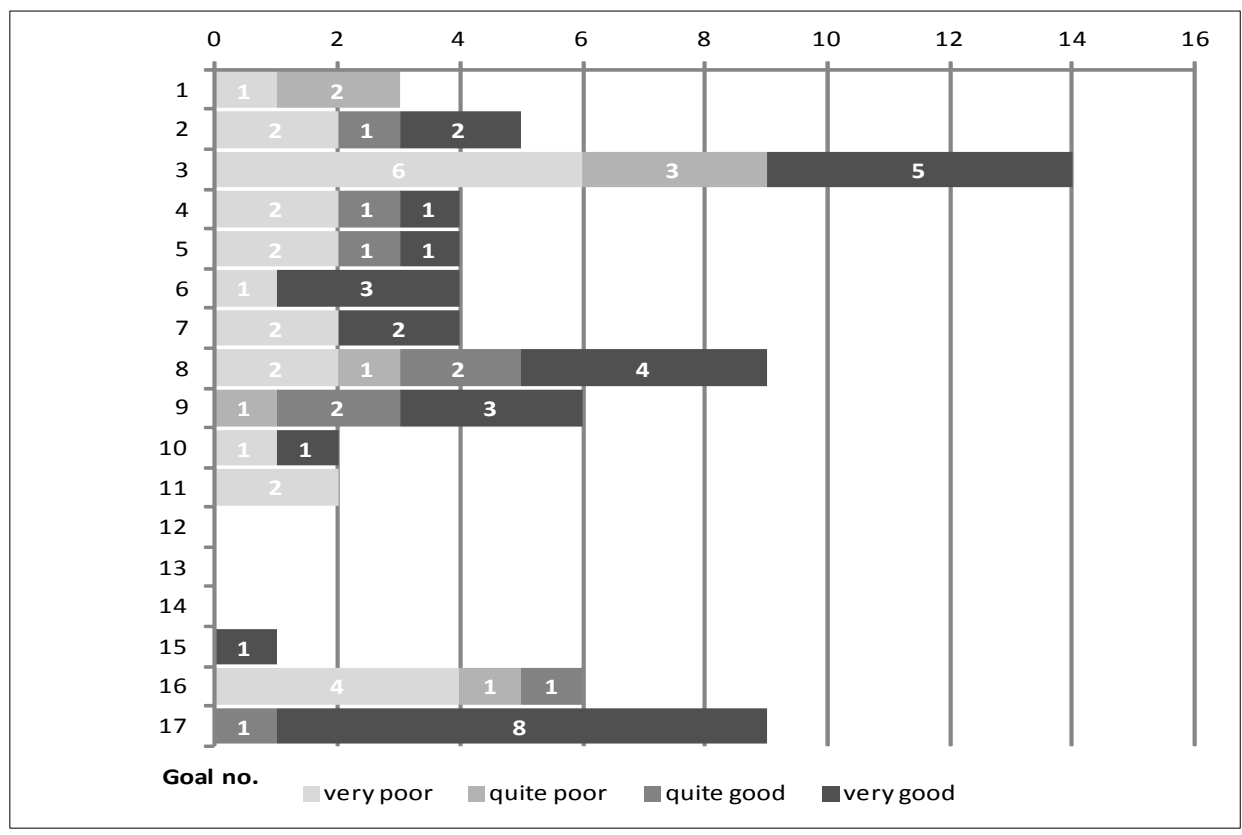

출처: 저자 작성

위〈그림 6〉은 각 목표별로 data frequency 점수가 어떻게 구성되어 있는지를 나타내고 있 다. 우선 전반적인 목표별 구성을 보면 네가지 점수구성이 골고루 되어 있음을 알 수 있다. 즉 각 목표들마다 구성 Tier1, Tier1/2 지표들의 data frequency가 구성지표에 따라 각기 큰 차이를 보이는 것이다. 그 중에서도 구성 지표 모두가 적어전체의 $50 \%$ 인 평균 8 개년 이상의 데이터를 제공하는 목표를 살펴보면 목표15(생물다양성), 목표17(이행수단·파트너십)을 들 수 있는데, 특히 목표15(생물다양성)의 경우 유일한 구성지표인 15.1.1(총 육지면적 중 산림 면적의 비율)은 평균 16 개년 데이터를 제공함으로써 최대값을 보이고 있다. 또한 목표17(이행수단파트너십)의 경우, quite good에 해당하는 17.6.2 (속도별 100명당 인터넷 광대역 사용자) 지표를 제외하고 나머지 8 개 지표 모두 very good에 해당함에 따라 평균 12개년 이상의 높은 data frequency를 보이고 있다.

이렇듯 상기의 Tier1, Tier1/2 지표 전체 및 각 목표별 차원에서의 data frequency를 분석하 였을 때, 두 분석 기준 모두에서 data frequency가 전반적으로 차이가 많이 남을 알 수 있다. 즉, 전체적 차원에서 보았을 때, 평균 8개년 이상의 데이터를 제공하는 지표의 개수가 총 40 개로 전체 대비 $54.8 \%$ 를 차지하는 반면, 그 이하의 데이터를 제공하는 지표의 개수 역시 23 개로 전체 대비 $45.2 \%$ 로 비슷한 수준을 보이고 있는 것이다. 하지만 2000 년 이후 data frequency가 평균 
1 개년에 그치는 지표의 개수가 12 개에 이르며, 평균 4 개년 이하의 data frequency를 가지는 지 표 총 개수 역시 25 개를 차지한다는 점을 볼 때 향후 안정적인 데이터 수집 및 분석을 위해서는 Tier1, Tier1/2 지표 내에서도 data frequency를 보완하여 향후 안정적으로 데이터를 매년 업데 이트 할 수 있도록 많은 노력이 필요한 부분이라 할 수 있다.

\section{5. 종합 분석: Data Availability}

데이터 이용가능성(Data Availability)이란, 상기의 country coverage와 data frequency의 점수를 종합적으로 고려하여 얼마나 많은 대상국가들로부터 얼마나 오랜 기간 동안 안정적으로 데이터를 획득할 수 있는가를 말한다. 따라서 country coverage와 data frequency 모두가 높을 수록 데이터 이용가능성은 높다고 할 수 있으며, 반대일 경우 데이터 이용가능성이 전반적으로 낮다는 평가가 가능하다.

상기에서 데이터 접근가능한(data-accessible) Tier1, Tier1/2 지표 73개를 도출하여, 해당 73 개 지표에 대한 country coverage와 data frequency를 각각 살펴보았다. 그렇다면 동 챕터 에서는 country coverage와 data frequency의 상관관계를 종합적으로 살펴봄으로써 SDGs 지 표의 전체적인 data availability를 평가하고자 한다.

아래〈표 10〉은 대상 73개 지표의 country coverage와 data frequency의 상관관계를 각각 네 가지 점수화 기준에 따라 분류하여 나타낸 표이다. 우선 분류점수를 세부적으로 살펴보면, country coverage와 data frequency가 가장 높은 상관관계를 보이는 부분은 둘 다 very good 점수를 받은 부분으로, 전체 73 개 지표 중 26 개 지표(34\%)가 이에 해당한다. 즉, 전체 193 개 $\mathrm{UN}$ 회원국 중 약 144 개 국가( $75 \%$ 이상)에 대해 2000년 이후부터 적어도 12 개년 이상의 데이터 를 획득할 수 있는 Tier1, Tier1/2 지표가 총 26 개인 것이다.

〈표 10〉대상지표의 Country Coverage와 Data Frequency 상관관계

\begin{tabular}{|c|c|c|c|c|c|c|}
\hline & \multicolumn{5}{|c|}{ Country Coverage } \\
\hline & & very poor & quite poor & quite good & very good & 합계 \\
\hline \multirow{5}{*}{$\begin{array}{c}\text { Data } \\
\text { frequency }\end{array}$} & very poor & 3 & 5 & 8 & 10 & 25 \\
\hline & quite poor & 0 & 0 & 5 & 2 & 8 \\
\hline & quite good & 0 & 2 & 2 & 5 & 9 \\
\hline & very good & 0 & 0 & 5 & 26 & 31 \\
\hline & 합 계 & 3 & 7 & 20 & 43 & 73 \\
\hline
\end{tabular}

출처: 저자 작성 
하지만 그 다음으로 높은 점수 $(10,8)$ 을 보인 부분을 살펴보면, country coverage의 경우 very good, quite good에 해당함에 따라 전반적으로 안정된 모습을 보이는 반면 data frequency의 경우 very poor에 해당함에 따라 data frequency는 지표간 간극(gap)이 매우 크 다는 점을 알 수 있다.

이러한 특징은 country coverage와 data frequency 상관관계에 대해 전체적인 차원에서 볼 때에도 마찬가지이다. Country Coverage 전체 적인 점수의 순위를 보면 very good과 quite good이 각각 43,20 으로, 두 점수를 합한 값은 73 개 지표 전체의 $86.3 \%$ 를 차지하고 있어 상당 히 안정적으로 국가를 포함하고 있다고 할 수 있다. 하지만 이에 반해 data frequency의 경우, very good의 점수를 31점으로 가장 높게 얻은 동시에 very poor 점수가 25점으로 그 뒤를 이음 에 따라 data frequency에 대한 지표간의 간극이 상당함을 알 수 있다. 특히 very poor에 해당 하는 총 25 개 지표 중에서 data frequency가 최하점인 ' 1 '점을 보이는 지표 개수가 12 개에 이른 다는 점은 이러한 문제 현상의 심각성을 보다 가중시킨다고 할 수 있다.

\section{〈그림 7〉 대상지표의 Country Coverage와 Data Frequency 상관관계 도식화}

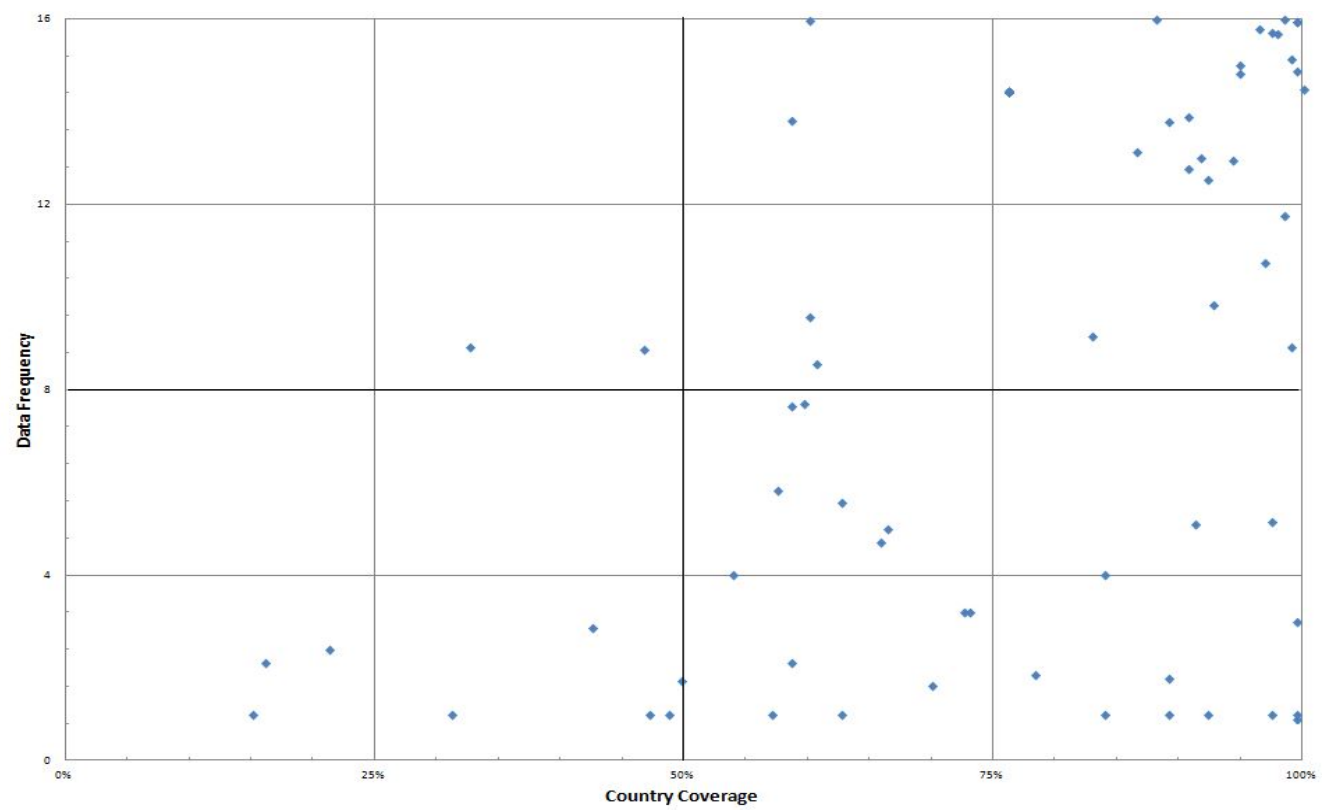

A: C.C(0<a $\leq 50), D \cdot F(0<a \leq 8), B: C \cdot C(0<a \leq 50), D \cdot F(8<a \leq 16), C: C . C(50<a \leq 100), D \cdot F(0<a \leq 8), D: C . C(50<a \leq$ 100), D.F( $8<\mathrm{a} \leq 16)$

출처: 저자 작성 
그런데 여기서 한 가지 주목할 부분은 data frequency 최하점인 1점을 보이는 지표들의 데이 터 담당 기관이다. $\mathrm{UNICEF}$ 는 데이터 접근이 가능한 총 73 개 지표 중에서 총 5 개 지표의 주요 데이터 담당 기관으로 지정되어 있는데, 5 개 지표 전체가 data frequency에서 최하점인 1점을 기록하고 있는 것이다. 따라서, 동 해당 지표들에 대해 UNICEF 자체만의 데이터를 활용하는 것 은 데이터의 지속적인 제공측면에서 매우 불안정하기 때문에 이에 대한 기타 관련기관들로부터 다른 대체 데이터를 얻거나 proxy를 얻을 수 있도록 해야할 것이다.

위〈그림 7〉은 상기의〈표 10〉상의 country coverage와 Data Frequency 상관관계를 도식 화한 그림이다. 위 그림에 대한 해석의 편의를 위해 총 16 개 구분을 good/poor 기준에 따라 네 가지(A,B,C,D)로 단순 점수화할 수 있는데 11$)$, 이러한 방식은 두 기준간의 상관관계를 보다 명확 히 보여준다는 점에서 용이하다. 위 그림 상에서 지표의 분포가 $\mathrm{C}$ 와 $\mathrm{D}$ 에 집중되어 있는 것을 통 해 확인 가능하듯, 전반적으로 country coverage는 안정적인 반면, Data frequency는 very good과 very poor 중심으로 각 점수대에 골고루 분포되어 있다는 점에서 지표간 간극이 크다고 종합진단이 가능하다.

또한 country coverage와 data frequency 상관관계를 목표별 차원에서 어떻게 구성되어 있 는지 살펴볼 때(〈표 11〉참조), 목표3(보건복지)과 목표17(이행수단·파트너십)이 전체적으로 가장 주목해서 볼 필요가 있다. 우선 목표3(보건복지)의 경우, $\mathrm{D}$ 영역에 해당하는 지표의 개수가 목표 17 다음으로 가장 많으며, country coverage와 data frequency 모두 very good에 해당하는 지표의 개수 역시 가장 많이 포함하고 있다. 특히 목표3을 구성하는 데이터 접근가능한 (data-accessible) 총 14 개 지표 모두가 $50 \%$ 이상의 country coverage를 보임으로써 상당히 안정적인 국별 자료 기반을 확보하고 있다. 하지만 목표3에서 또 한 가지 주목할 부분은 이러한 높은 country coverage에도 불구하고 data frequency의 경우 그 간극이 유독 크다는 점이다. 즉, 전체 14 개 지표에서 목표 3 은 5 개 지표에서 very good 점수를 보이고 그 중에서도 2 개 지표 는 15.9 이상의 매우 높은 성적을 보임에도 불구하고 1 점 이하의 지표를 3 개나 가지고 있음에 따 라 총 9 개의 1점 이하 지표 중에서 가장 많은 비중을 차지하고 있는 것이다.

11) 4 가지 점수구분은 다음과 같이 정의한다.

\begin{tabular}{|c|c|c|c|c|c|}
\hline & & \multicolumn{4}{|c|}{ Country Coverage } \\
\hline & & very poor & quite poor & quite good & very good \\
\hline \multirow{4}{*}{ Data frequency } & very poor & \multirow{2}{*}{\multicolumn{2}{|c|}{$\begin{array}{c}A \\
C . C(0<a \leq 50), \text { D.F }(0<a \leq 8)\end{array}$}} & \multirow{2}{*}{\multicolumn{2}{|c|}{$\begin{array}{c}C \\
\text { C.C }(50<a \leq 100), \quad \text { D.F }(0<a \leq 8)\end{array}$}} \\
\hline & quite poor & & & & \\
\hline & quite good & \multirow{2}{*}{\multicolumn{2}{|c|}{$\begin{array}{c}\text { B } \\
\text { C.C }(0<a \leq 50), \text { D.F }(8<a \leq 16)\end{array}$}} & \multirow{2}{*}{\multicolumn{2}{|c|}{$\begin{array}{c}D \\
\text { C.C }(50<a \leq 100), D \cdot F(8<a \leq 16)\end{array}$}} \\
\hline & very good & & & & \\
\hline
\end{tabular}

출처: 저자 작성 
〈표 11〉목표별 Country coverage \& Data Frequency 상관관계

\begin{tabular}{|c|c|c|c|c|c|c|}
\hline Goal & $A$ & B & $C$ & $D$ & $\begin{array}{l}\text { Very good on } \\
\text { CC\&DF }\end{array}$ & $\begin{array}{l}\text { Very poor on } \\
\text { CC\&DF }\end{array}$ \\
\hline 1 & & & 3 & & & \\
\hline 2 & & & 2 & 3 & 1 & \\
\hline 3 & & & 8 & 6 & 4 & \\
\hline 4 & 2 & & & 2 & & 2 \\
\hline 5 & 1 & & 1 & 1 & 1 & 1 \\
\hline 6 & & & 1 & 3 & 3 & \\
\hline 7 & & & 2 & 2 & 2 & \\
\hline 8 & & 2 & 3 & 5 & 3 & \\
\hline 9 & & & 1 & 5 & 3 & \\
\hline 10 & 1 & & & 1 & 1 & \\
\hline 11 & 2 & & & & & \\
\hline 12 & & & & & & \\
\hline 13 & & & & & & \\
\hline 14 & & & & & & \\
\hline 15 & & & & 1 & 1 & \\
\hline 16 & 2 & & 3 & 1 & & \\
\hline 17 & & & & 9 & 7 & \\
\hline 소계 & 8 & 2 & 24 & 39 & 26 & 3 \\
\hline 합계 & \multicolumn{4}{|c|}{73} & 26 & 3 \\
\hline
\end{tabular}

A: $C . C(0<a \leq 50), \quad D . F(0<a \leq 8), B: C . C(0<a \leq 50), \quad D . F(8<a \leq 16), C: C . C(50<a \leq 100), \quad D . F(0<a \leq 8), D: C . C(50<a \leq$ 100), D.F( $8<a \leq 16)$

출처: 저자 작성

다음으로 목표17(이행수단파트너십)의 경우에는 데이터 접근가능한(data-accessible) 총 9개 지표 모두 $\mathrm{D}$ 영역에 포함됨에 따라 다른 목표들에 비해 가장 높은 country coverage와 data frequency들로만 구성되어 있다고 할 수 있다. 그 중에서도 특히 country coverage의 경우 최 대값인 $100 \%$ 에 해당하는 지표를 비롯해 총 4 개의 지표가 $90 \%$ 이상의 높은 점수를 보이고 있으 며, 전반적으로 매우 상이하게 분포되어 있는 data frequency의 경우에도, 목표 17 의 경우 모두 quite good과 very good으로만 구성되어 있다는 점에서 가장 안정적으로 data frequency를 확 보하고 있다고 할 수 있다.

또한 73 개 각각의 지표 수준에서 살펴보면, (1) 3.2.1(5세 이하 아동 사망률), (2) 3.2.2(신생아 사망률), (3) 15.1.1(총 육지면적 중 산림면적의 비율) 등 총 3개의 지표에서 country coverage 와 data frequency 모두 최대값에 근접한 점수가 보인다는 점에서, 전체 중 가장 높은 data availability를 갖는 지표들이라 할 수 있다. 
이렇듯 상기의 일련의 분석들을 통해서 보았을 때, 데이터 접근이 가능한(data-accessible) 73개 Tier1, Tier1/2 지표들의 전반적인 data availability는 비교적 평가가능하다. 특히 country coverage의 경우 비교적 안정적인 모습을 보이고 있으나, data frequency의 경우 지표 에 따라 그 편차가 크다고는 할 수 있다는 점에서 종합적으로 보았을 때는 둘 간의 상관관계에서 $\mathrm{C}, \mathrm{D}$ 영역에 해당하는 부분이 높음을 알 수 있다.

하지만 사실상 17 개 목표 각각의 이행 진척도를 제대로 측정하기 위해서는 각 지표들 마다 193 개 국가 모두 뿐만 아니라 다년간 충분한 데이터를 반드시를 확보함으로써 언제든지 해당 데 이터 추적이 가능한 수준이 되어야만이 가능하다. 이러한 측면에서 종합적으로 SDGs Tier1, Tier1/2 지표의 data availability를 보면 193개 대상 국가들의 포함 비중은 비교적 높은 반면 데이터 이용가능 연도수는 상대적으로 불안정함에 따라 전체적인 data availability가 안정되지 못하다는 결론을 도출할 수 있다.

이러한 결론과 함께, 동 연구에서의 data availability 분석 결과를 SDGs 지표 전체로 확장하 여 생각해볼 수도 있다. 먼저, Tier1, Tier1/2에 해당하지만 실제 접근가능한 데이터가 부재한 목표12, 목표13과 함께, Tier1, Tier1/2 지표자체가 부재한 목표13(기후변화)을 포함해 나머지 Tier2, Tier3, Tier2/3, Tier1/2/3, Untiered 지표 모두를 포함하면 전체 대상지표개수는 241 개(중복제외시 230개)로 늘어나는 반면 현재 기준 이용가능한 지표 개수는 변동이 없기 때문에 전체적인 데이터 이용가능성이 현저히 떨어질 수밖에 없는 것이다. 이렇듯 data availability 논 의를 SDGs 지표 전체 차원으로 확장하였을 때는 그만큼 데이터에 접근조차 불가한 지표의 개수 까지 포함된다는 점에서 보다 회의적인 결론이 도출되지만, 동 연구에서의 data availability 논 의를 위한 분석대상인 Tier1, Tier1/2 지표 범위자체가 사실상 SDGs 전체 차원에서 보았을 때 도 데이터 이용가능성을 논하기 위한 유의미한 지표 범위와 일치한다는 점에서 98개(중복제외시 96 개) 지표를 대상으로 한 동 연구의 결과로 SDGs 지표 전체에 대한 분석 결과를 대체하여 해석 하는데 큰 무리가 없다고 할 수 있다.

\section{IV. 결어}

앞에서 본 바와 같이, 현재 데이터 이용가능성이 가장 높다고 분류되어 있는 Tier1, 그리고 좀 더 확장하여 Tier $1 / 2$ 지표를 보았을 때, 시실상 제안된 보고서상의 분류체계와 현실간의 간극이 존재함을 알 수 있다. 즉 최종지표 선정과정에서 실질적인 데이터 이용가능성을 고려하고자 하는 
노력이 부족했다고 할 수 있는 것이다.

이렇게 지표상의 데이터 이용가능성이 결여되면 실질적으로 $\mathrm{SDGS}$ 를 이행하고 모니터링하는데 현실적인 한계를 노정할 수밖에 없다. 이로 인해 SDGs의 본격적인 달성노력이 2016년부터 시작 되었음에도 불구하고, SDGs를 완전하게 이행하고 모니터링하기 위한 기반자체가 불완전하여 이 를 보완하기 위한 추가 노력과 시간이 앞으로 더욱 필요하게 되는 것이다(Dunning and Kalow, 2016a).

물론 글로벌 지표 체계 수립이 현재 완전히 끝난 것은 아니다. IAEG-SDGs는 앞으로도 tier system을 보완하고 2030년까지 지표와 모니터링 체계를 개선하기 위한 기술적인 지원을 해나갈 것이다. 따라서 현단계에서 IAEG-SDGs가 발표한 글로벌 지표 체계에 대해서 단정적인 평가를 내리는 것은 적절치 않다. 하지만 지난 3 월 UNSC의 최종지표 및 지표체계 발표 이후, 많은 국가 들이 이에 맞추어 SDGs 이행을 위한 움직임을 본격적으로 시작하고 있다는 점에서 지역차원, 국 내차원에서의 SDGs 이행체계 마련에 있어 기준이 될 글로벌 지표 체계가 보다 안정적이고 모범 적으로 작동해야할 필요가 있다. 그리고 그 중에서도 가장 이용가능성이 높다고 제시한 Tier1 지 표가 갖는 기대는 더욱 클 것이다. 하지만 동 분석 결과 현재 제시된 Tier1, 그리고 좀 더 나아가 Tier1/2 지표의 데이터 이용가능성을 살펴보았을 때, 국가포함수준(country coverage) 비교적 안정적인 반면, 데이터 빈도수(data frequency)는 상대적으로 불충분함에 따라 전반적인 데이터 이용가능성과 실제간의 간극(gap)이 존재한다고 할 수 있다.

$\mathrm{SDGs}$ 각 목표를 효과적으로 이행하고 이행 정도를 제대로 측정하기 위해서는 230 개 지표 전 체에 대해 193 개 국가 모두 뿐만 아니라 다년간의 충분한 데이터 확보가 보장되어 언제든지 데이 터를 추적할 수 있는(trackable) 체제가 되어야 한다. 또한 각 지표들이 요구하는 수준대로 세분 화된 데이터를 확보할 수도 있어야 한다(Dunning and Kalow, 2016a). 이를 위해 현재 글로벌 지표 체계가 어떻게 구성되어 있고 실질적으로 지역 및 국가 차원의 SDGs 이행체계를 잇는 플랫 폼으로서 제대로 작동하고 있는지에 대해 동 연구에서와 같은 면밀한 중간 점검을 실시할 필요가 있다. 이렇게 할 때에만이 IAEG-SDGs를 중심으로 현재 이루어지고 있는 글로벌 지표체계 자체 의 개선작업이 보다 효과적으로 이루어질 수 있을 뿐만 아니라, 하위 단계에서의 SDGs 이행체계 마련 과정에서도 표준화된 글로벌 지표체계를 반영함으로써 보다 일관된 SDGs 이행 및 모니터링 이 가능해질 수 있기 때문이다. 


\section{〈참고문헌〉}

김지현. 2016. “SDGs 지표 확정과 의의" 개발과 이슈』제 25호. 성남: 한국국제협력단 (발간예정)

제 I 장

제 II 장

섹

터

제 III 장

Dunning, Casey and Kalow, Jared. 2016a. "SDG Indicators: Serious Gaps abound in Data Availability”, posted on official website of Center for Global Development(CGD) (2016.05.17), available at http://www.cgdev.org/blog/sdgindicators-serious-gaps-abound-data-availability (접속일: 2016.07.15)

2016b. “What SDGs Can We Track Now?” posted on official website of

Center for Global Development(CGD) (2016.06.10), available at http://www.cgdev.org/ blog/what-sdgs-can-we-track-now（접속일: 2016.07.15)

IISD. “News: SDG Group Discusses Indicator Selection, Way Forward” posted on 2 June 2015 on IISD website, available at http://sd.iisd.org/news/sdg-groupdiscusses-indicator-selection-way-forward/ (접속일:2016.07.15)

UN 대표홈페이지: un.org 


\begin{tabular}{|c|c|c|c|c|c|c|c|c|c|c|c|c|c|c|}
\hline 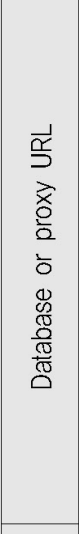 & 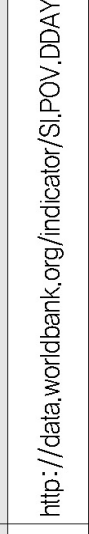 & 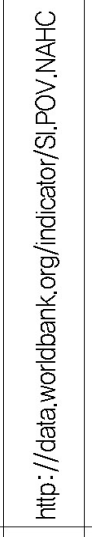 & 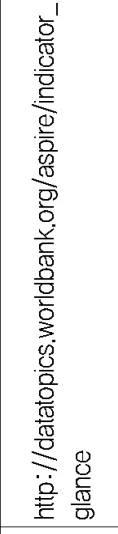 & 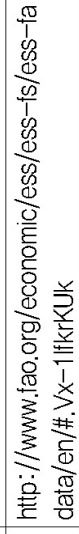 & 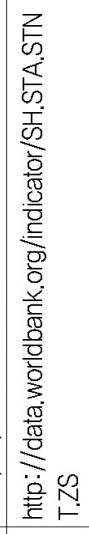 & 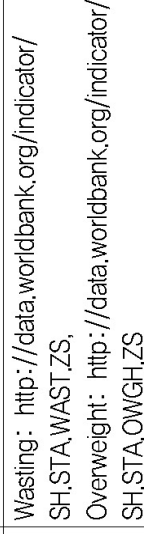 & 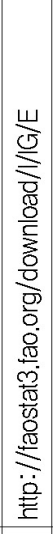 & 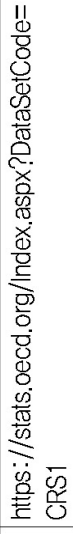 & 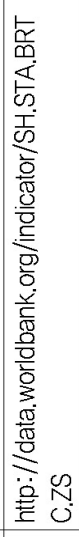 & 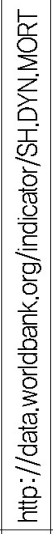 & 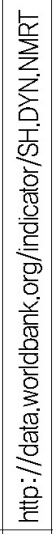 & 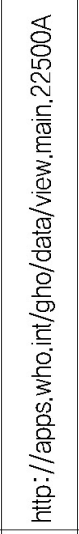 & 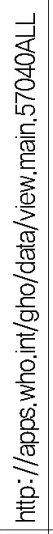 & 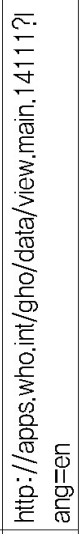 \\
\hline 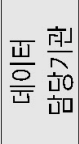 & 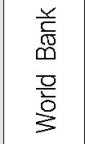 & 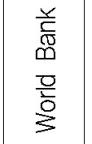 & 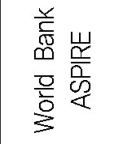 & 委 & 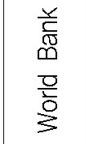 & 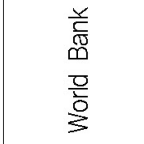 & 운 & 운 & 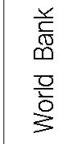 & 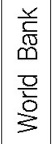 & 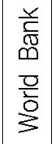 & ㅇㅗㅗ & 울 & 올 \\
\hline 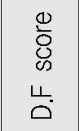 & $\begin{array}{l}\overline{\bar{o}} \\
\frac{8}{0} \\
\frac{0}{\bar{y}}\end{array}$ & $\begin{array}{l}\bar{z} \\
\frac{8}{0} \\
\frac{0}{\bar{y}}\end{array}$ & $\begin{array}{l}\overline{0} \\
\frac{8}{8} \\
\frac{1}{1}\end{array}$ & $\begin{array}{l}\overline{8} \\
8 \\
\frac{0}{9}\end{array}$ & $\begin{array}{l}\bar{z} \\
\frac{2}{2} \\
\frac{1}{9}\end{array}$ & $\begin{array}{l}\frac{1}{8} \\
\frac{8}{2} \\
\frac{2}{9}\end{array}$ & \begin{tabular}{|l|}
8 \\
8 \\
8 \\
0 \\
$\frac{0}{\bar{y}}$
\end{tabular} & $\begin{array}{l}\overline{8} \\
8 \\
\frac{0}{9}\end{array}$ & $\begin{array}{l}\bar{y} \\
\frac{1}{2} \\
0 \\
\frac{0}{\bar{y}}\end{array}$ & $\begin{array}{l}7 \\
8 \\
0 \\
2 \\
9\end{array}$ & $\begin{array}{l}7 \\
8 \\
0 \\
2 \\
9\end{array}$ & $\begin{array}{l}\frac{2}{8} \\
\frac{2}{3} \\
\frac{1}{3}\end{array}$ & $\begin{array}{l}\overline{8} \\
8 \\
2 \\
\frac{2}{9}\end{array}$ & $\begin{array}{l}\frac{1}{8} \\
\frac{8}{2} \\
\frac{2}{3}\end{array}$ \\
\hline$\frac{4}{0} \cdot \frac{\bar{D}}{3}$ & $\begin{array}{l}10 \\
10 \\
10\end{array}$ & F & $\bar{\sim}$ & $\begin{array}{l}\mathscr{8} \\
\stackrel{8}{10} \\
\stackrel{10}{2}\end{array}$ & $\frac{\mathscr{g}}{\dot{m}}$ & $\stackrel{\sim}{\sim}$ & $\begin{array}{l}0 \\
0 \\
\infty \\
\infty\end{array}$ & $\begin{array}{l}\underset{J}{ \pm} \\
\underset{ \pm}{*}\end{array}$ & E & 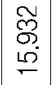 & $\begin{array}{l}\widetilde{\Xi} \\
\widetilde{\sigma} \\
\stackrel{\sim}{n}\end{array}$ & $\nabla$ & $\begin{array}{l}\infty \\
\infty \\
\underset{\forall}{ } \\
\end{array}$ & $\forall$ \\
\hline 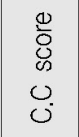 & $\begin{array}{l}\overline{8} \\
8 \\
8 \\
\frac{1}{5} \\
0\end{array}$ & $\begin{array}{l}\overline{8} \\
8 \\
8 \\
\frac{1}{5} \\
8\end{array}$ & $\begin{array}{l}\overline{8} \\
8 \\
8 \\
\frac{0}{\overline{3}} \\
\overline{8}\end{array}$ & $\begin{array}{l}\overline{8} \\
8 \\
0 \\
\frac{0}{\bar{y}}\end{array}$ & $\begin{array}{l}\overline{8} \\
8 \\
0 \\
\frac{0}{5}\end{array}$ & $\begin{array}{l}\overline{8} \\
8 \\
8 \\
\frac{1}{7} \\
\frac{7}{5}\end{array}$ & $\begin{array}{l}\overline{8} \\
8 \\
0 \\
0 \\
\frac{0}{5} \\
5\end{array}$ & $\begin{array}{l}8 \\
8 \\
8 \\
8\end{array}$ & $\begin{array}{l}\overline{8} \\
8 \\
\frac{0}{9}\end{array}$ & $\begin{array}{l}8 \\
8 \\
8 \\
8 \\
9\end{array}$ & $\begin{array}{l}8 \\
8 \\
8 \\
2 \\
9\end{array}$ & $\begin{array}{l}8 \\
8 \\
8 \\
2 \\
\frac{8}{>}\end{array}$ & $\begin{array}{l}8 \\
8 \\
8 \\
\frac{2}{9}\end{array}$ & $\begin{array}{l}8 \\
8 \\
8 \\
\Phi \\
\frac{1}{5}\end{array}$ \\
\hline$0 \longdiv { 0 }$ & ๕ి & ¿̊ & 今े & 今̊ & $\frac{\circ}{\stackrel{⿰}{\sim}}$ & 总 & $\frac{\circ}{6}$ & @̊ & $\frac{\circ}{\sigma}$ & \&̊요 & $\stackrel{\circ}{\circ}$ & 畄 & $\stackrel{\circ}{\circ}$ & 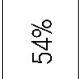 \\
\hline 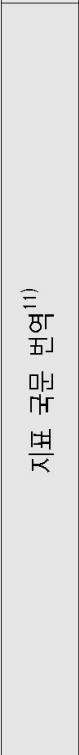 & 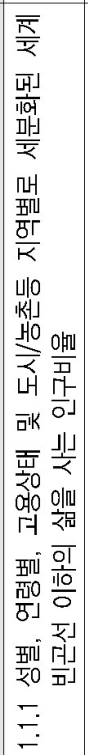 & 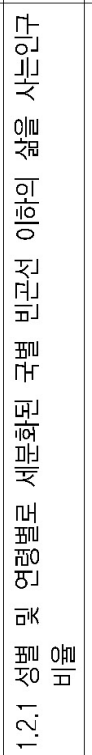 & 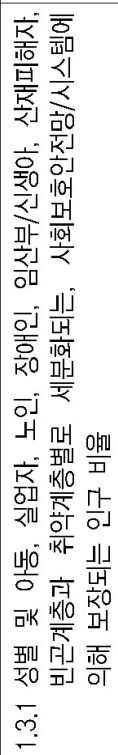 & 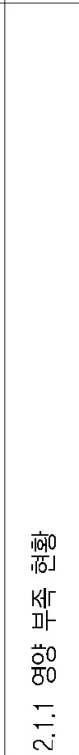 & 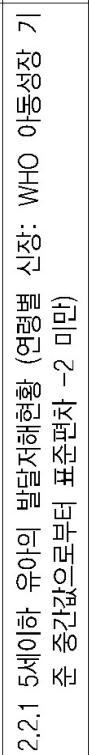 & 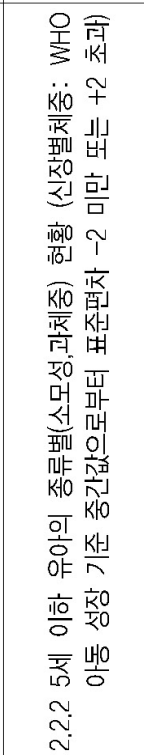 & 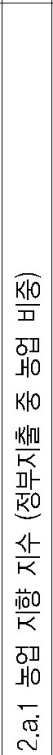 & 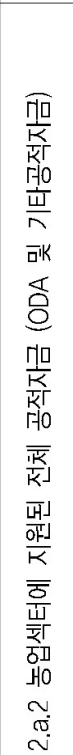 & 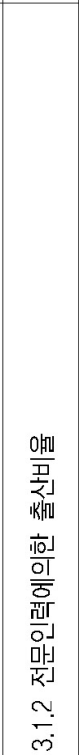 & 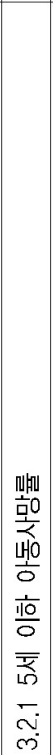 & 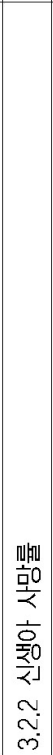 & 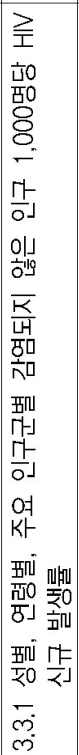 & 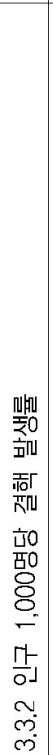 & 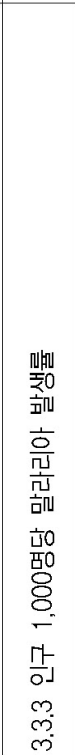 \\
\hline
\end{tabular}




\begin{tabular}{|c|c|c|c|c|c|c|c|c|c|c|c|c|c|c|c|}
\hline 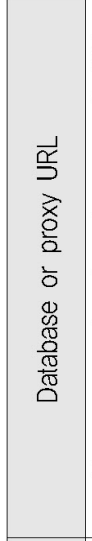 & 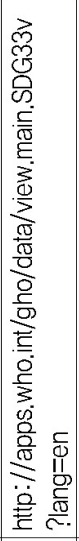 & 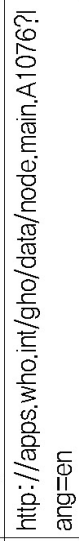 & 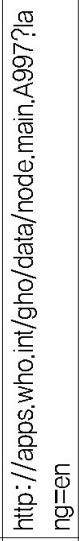 & 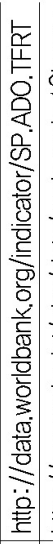 & 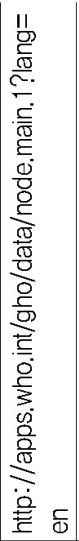 & 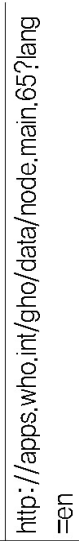 & 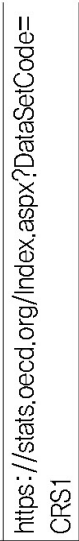 & 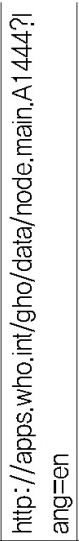 & 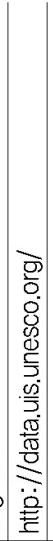 & 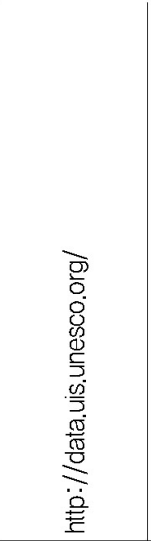 & 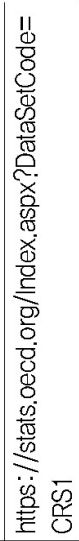 & 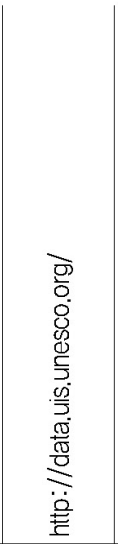 & 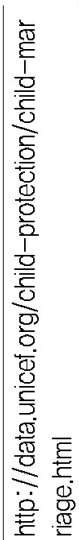 & 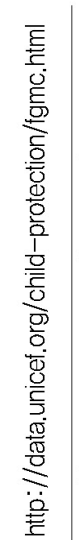 & 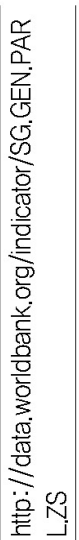 \\
\hline 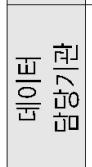 & $\begin{array}{l}\text { 울 } \\
\text { 3 }\end{array}$ & 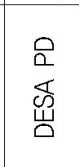 & ㅇㅜㅗ & 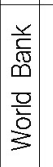 & 운 & ㅇㅗㅗ & 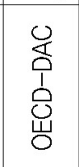 & 울 & 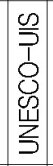 & 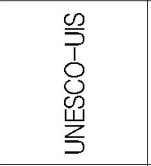 & $\begin{array}{l}8 \\
\text { 岁 }\end{array}$ & 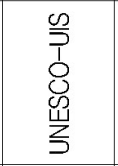 & 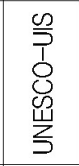 & $\frac{\text { 岀 }}{\underline{ٍ}}$ & 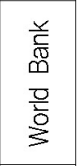 \\
\hline 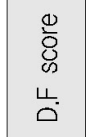 & $\begin{array}{l}\overline{0} \\
\frac{8}{2} \\
\frac{0}{3}\end{array}$ & $\begin{array}{l}\overline{0} \\
\frac{0}{2} \\
\frac{0}{9}\end{array}$ & $\begin{array}{l}\overline{0} \\
\frac{1}{2} \\
\frac{1}{9}\end{array}$ & $\begin{array}{l}8 \\
8 \\
0 \\
2 \\
0 \\
3\end{array}$ & $\begin{array}{l}\bar{z} \\
\frac{8}{2} \\
\bar{g}\end{array}$ & 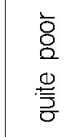 & $\begin{array}{l}\frac{8}{8} \\
\frac{8}{8} \\
\frac{2}{9}\end{array}$ & 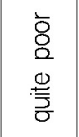 & 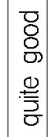 & $\begin{array}{l}\overline{8} \\
\frac{8}{2} \\
\frac{1}{9}\end{array}$ & $\begin{array}{l}\overline{8} \\
8 \\
0 \\
\frac{2}{9}\end{array}$ & $\begin{array}{l}\overline{0} \\
\frac{8}{2} \\
\frac{1}{9}\end{array}$ & $\begin{array}{l}\frac{1}{8} \\
\frac{8}{2} \\
\frac{8}{9}\end{array}$ & $\begin{array}{l}\overline{8} \\
\frac{8}{8} \\
\frac{2}{9}\end{array}$ & $\stackrel{y}{2}$ \\
\hline 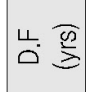 & $\stackrel{\circ}{\circ}$ & - & - & 120 & - & 10 & $\underset{⿱ 亠 乂}{\forall}$ & $\underset{\text { in }}{+}$ & $\begin{array}{l} \pm \\
\stackrel{0}{0}\end{array}$ & ঙ্ণ & $\begin{array}{l}\underset{J}{⿰} \\
\dot{y}\end{array}$ & $\bar{\sim}$ & - & - & 2 \\
\hline 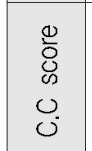 & 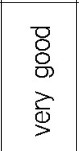 & 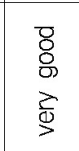 & $\begin{array}{l}\overline{8} \\
8 \\
8 \\
8\end{array}$ & $\begin{array}{l}\overline{8} \\
8 \\
8 \\
7 \\
9 \\
9\end{array}$ & $\begin{array}{l}8 \\
8 \\
8 \\
z \\
9\end{array}$ & $\begin{array}{l}\overline{8} \\
8 \\
\overline{0} \\
\overline{\bar{y}}\end{array}$ & $\begin{array}{l}\overline{8} \\
\frac{8}{8} \\
\frac{\bar{m}}{\bar{y}}\end{array}$ & $\begin{array}{l}8 \\
8 \\
8 \\
\frac{0}{3}\end{array}$ & $\begin{array}{l}7 \\
8 \\
0 \\
2 \\
0\end{array}$ & $\begin{array}{l}\overline{8} \\
8 \\
\frac{2}{1}\end{array}$ & $\begin{array}{l}\overline{8} \\
8 \\
\overline{0} \\
\overline{0} \overline{\bar{\sigma}}\end{array}$ & $\begin{array}{l}\overline{\mathrm{g}} \\
\mathrm{a} \\
\grave{\mathrm{g}}\end{array}$ & $\begin{array}{l}\overline{8} \\
8 \\
0 \\
0 \\
\frac{0}{0}\end{array}$ & 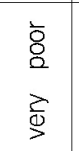 & $\Phi$ \\
\hline$u \stackrel{0}{0}$ & 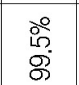 & $\frac{\circ}{\circ}$ & ふे & 品 & $\frac{\circ}{\circ}$ & \&े & @ & $\frac{2^{\circ}}{\sigma}$ & $\frac{20}{5}$ & $\stackrel{\circ 0}{\check{c}}$ & $\gtreqless$ & $\stackrel{\circ}{@}$ & வे & 号 & 8 \\
\hline 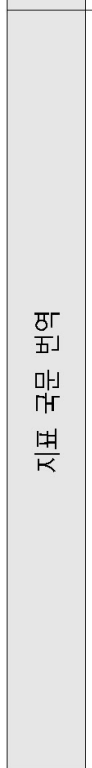 & 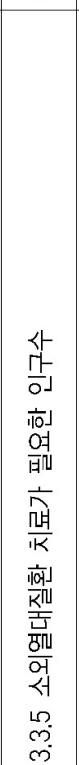 & 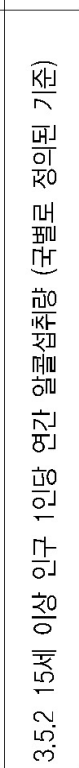 & 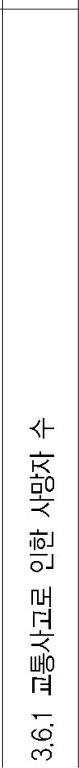 & 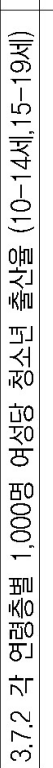 & 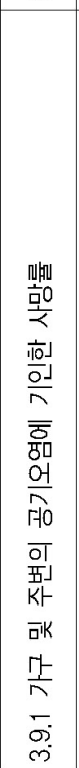 & 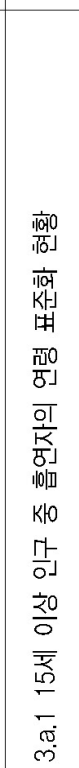 & 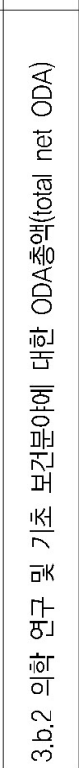 & 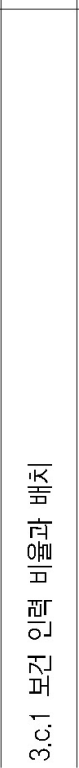 & 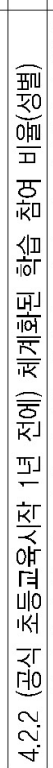 & 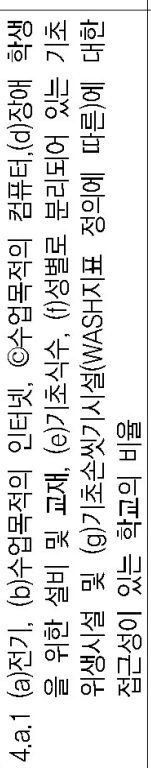 & 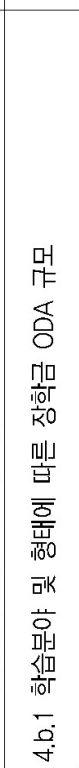 & 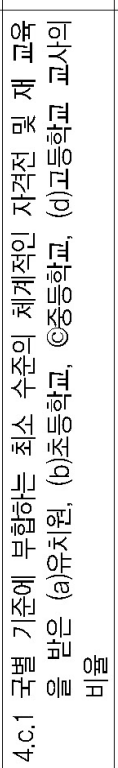 & 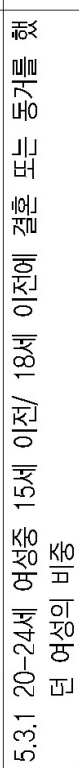 & 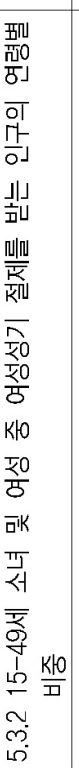 & $\frac{\frac{1-1}{101}}{\text { o| }}$ \\
\hline
\end{tabular}




\begin{tabular}{|c|c|c|c|c|c|c|c|c|c|c|c|}
\hline 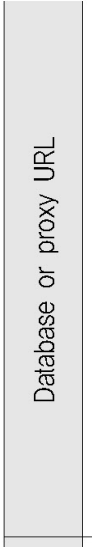 & 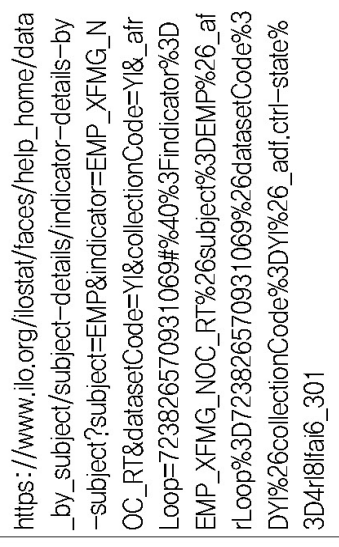 & 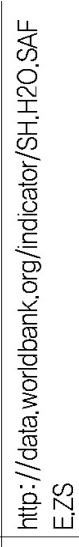 & 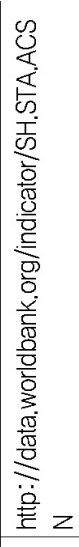 & 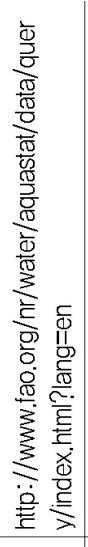 & 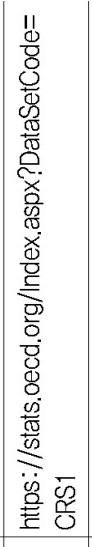 & 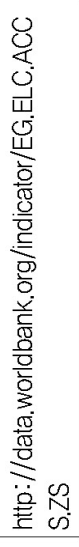 & 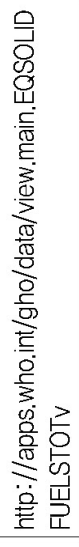 & 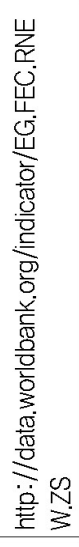 & 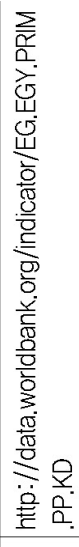 & 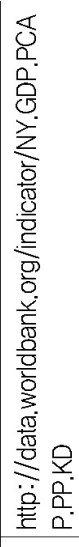 & 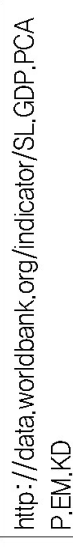 \\
\hline 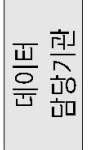 & $\stackrel{\rho}{=}$ & 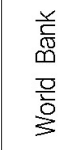 & $\sum_{\zeta}^{0}$ & 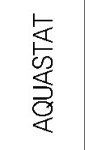 & 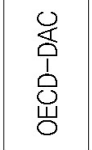 & 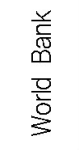 & 울 & 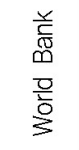 & 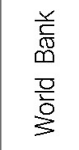 & 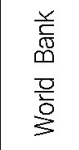 & 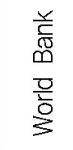 \\
\hline 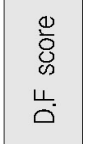 & $\begin{array}{l}\overline{8} \\
8 \\
0 \\
00 \\
\frac{0}{\bar{y}}\end{array}$ & $\begin{array}{l}\overline{8} \\
8 \\
\overline{0} \\
\frac{1}{9}\end{array}$ & $\begin{array}{l}\overline{8} \\
8 \\
0 \\
\frac{2}{9}\end{array}$ & $\begin{array}{l}\frac{\overline{8}}{8} \\
\frac{2}{9}\end{array}$ & $\begin{array}{l}\overline{8} \\
8 \\
\frac{0}{9} \\
\frac{2}{9}\end{array}$ & $\begin{array}{l}\overline{0} \\
\frac{8}{2} \\
\frac{0}{9}\end{array}$ & $\begin{array}{l}\frac{1}{8} \\
\frac{8}{2} \\
\frac{1}{3}\end{array}$ & $\begin{array}{l}\overline{8} \\
8 \\
\square \\
\frac{7}{9}\end{array}$ & $\begin{array}{l}\overline{8} \\
8 \\
0 \\
\frac{2}{9}\end{array}$ & $\begin{array}{l}\overline{8} \\
\dot{0} \\
i \overline{0}\end{array}$ & $\begin{array}{l}\overline{8} \\
8 \\
\frac{8}{9}\end{array}$ \\
\hline$\stackrel{u}{\Delta} \cdot \bar{\Phi}$ & $\underset{\infty}{\widetilde{\infty}}$ & 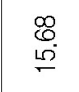 & 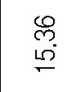 & $\stackrel{?}{=}$ & $\begin{array}{l}\text { f } \\
\dot{f}\end{array}$ & $m$ & - & $\stackrel{\stackrel{\Delta}{0}}{\simeq}$ & 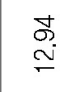 & $\begin{array}{l}\stackrel{\infty}{\infty} \\
\stackrel{+}{+}\end{array}$ & $\oplus$ \\
\hline 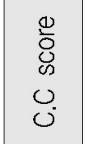 & $\begin{array}{l}\overline{\bar{z}} \\
\bar{\square} \\
\overline{\underline{0}} \\
\overline{\bar{y}}\end{array}$ & $\begin{array}{l}\overline{8} \\
8 \\
\stackrel{8}{9}\end{array}$ & $\begin{array}{l}8 \\
8 \\
8 \\
\frac{1}{>}\end{array}$ & $\begin{array}{l}8 \\
8 \\
8 \\
\frac{8}{9}\end{array}$ & $\begin{array}{l}8 \\
8 \\
8 \\
\frac{9}{9}\end{array}$ & $\begin{array}{l}8 \\
8 \\
8 \\
\frac{8}{>}\end{array}$ & 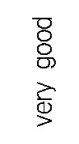 & $\begin{array}{l}\overline{8} \\
\mathrm{a} \\
\stackrel{8}{>}\end{array}$ & $\begin{array}{l}\overline{8} \\
\mathrm{o} \\
\grave{9}\end{array}$ & $\begin{array}{l}\overline{8} \\
8 \\
\stackrel{0}{10} \\
>\end{array}$ & $\begin{array}{l}\overline{8} \\
8 \\
\frac{8}{9}\end{array}$ \\
\hline$\because \dot{0}$ & 吕 & ஓे & な̊ & 今े & $\gtreqless$ & ஓ̊요 & ஓे & ๙ั & ஓ̊̊̆ & 号 & $\stackrel{\circ}{\infty}$ \\
\hline 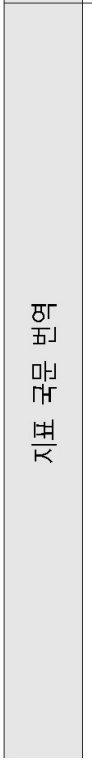 & 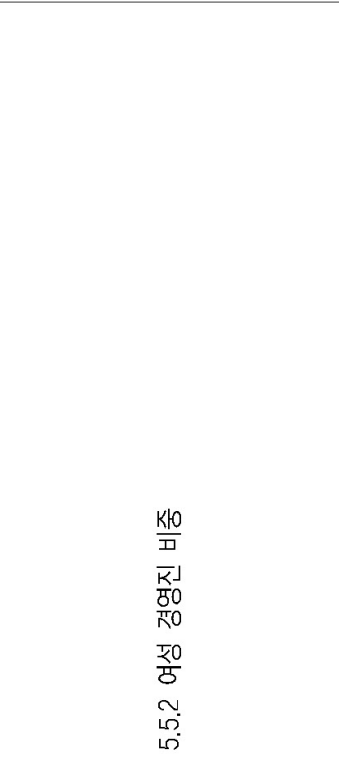 & 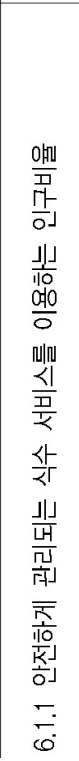 & 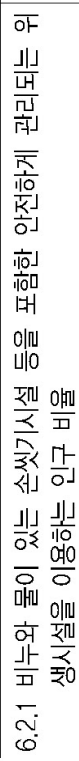 & 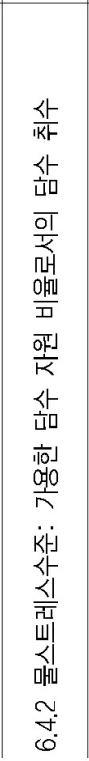 & 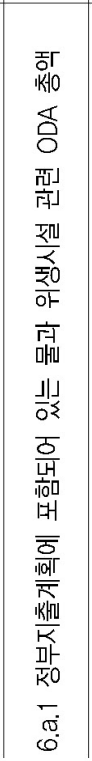 & 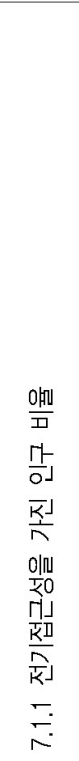 & 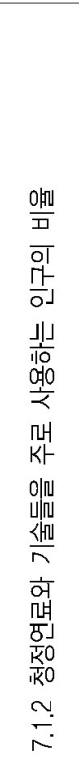 & 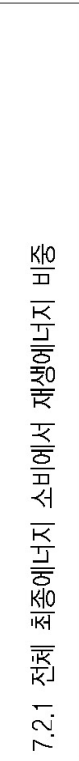 & 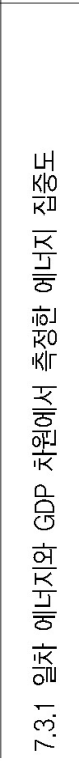 & 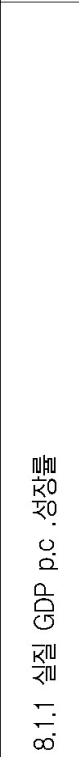 & 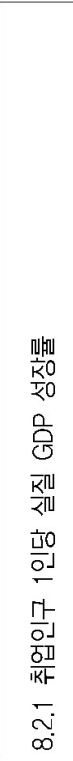 \\
\hline
\end{tabular}




\begin{tabular}{|c|c|c|c|c|c|c|c|}
\hline 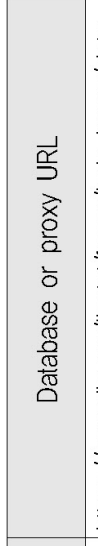 & 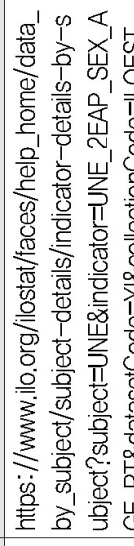 & 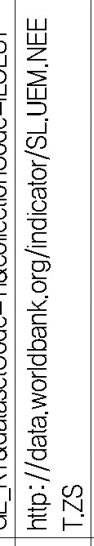 & 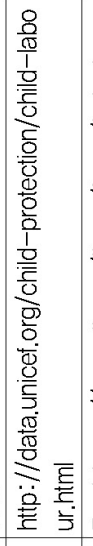 & 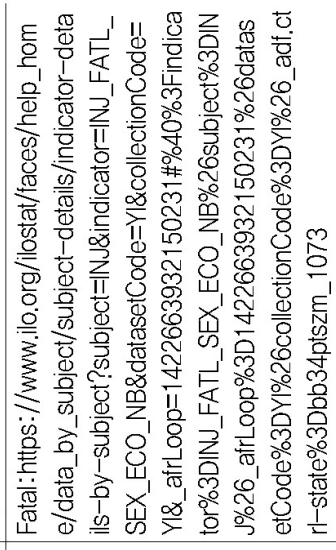 & 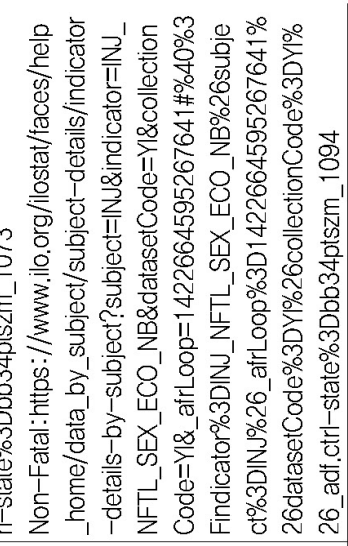 & 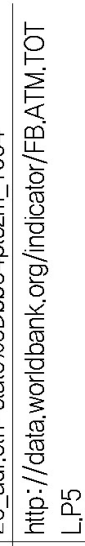 & 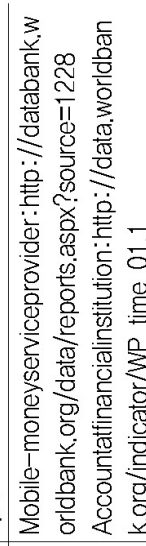 \\
\hline 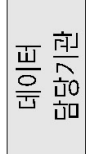 & $\stackrel{\rho}{=}$ & 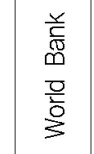 & 岀 & & $\stackrel{\mathrm{g}}{\mathrm{g}}$ & 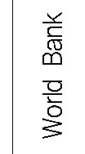 & 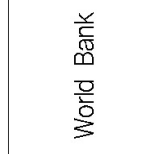 \\
\hline 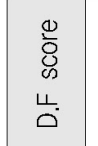 & 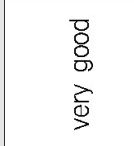 & 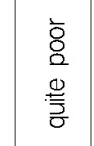 & 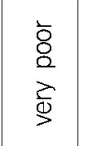 & & 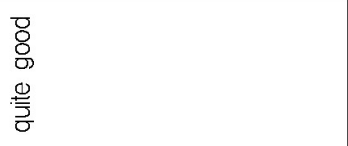 & $\begin{array}{l}\overline{0} \\
\mathrm{o} \\
0 \\
0 \overline{\bar{y}}\end{array}$ & 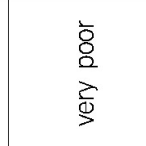 \\
\hline 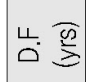 & $\stackrel{m}{-}$ & 兽 & - & & $\begin{array}{l}\infty \\
\substack{\infty \\
\infty}\end{array}$ & 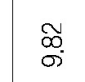 & $\stackrel{\leftrightarrow}{\infty}$ \\
\hline 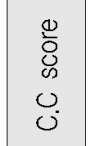 & $\begin{array}{l}0 \\
.8 \\
0 \\
\overline{0} \\
0\end{array}$ & 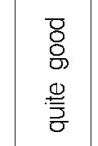 & 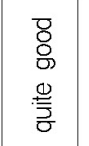 & & 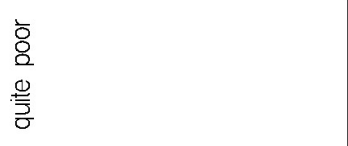 & $\begin{array}{l}\overline{0} \\
\stackrel{8}{0} \\
\dot{z} \\
\bar{y}\end{array}$ & 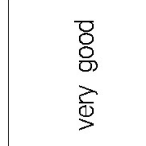 \\
\hline $\begin{array}{l}0 \\
ن\end{array}$ & ఏ̊ & 今े & 产 & & 总 & 号 & $\stackrel{\circ}{\circ}$ \\
\hline 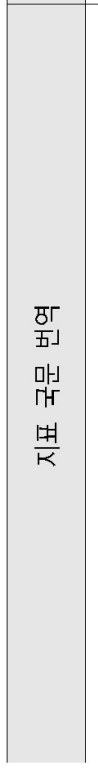 & 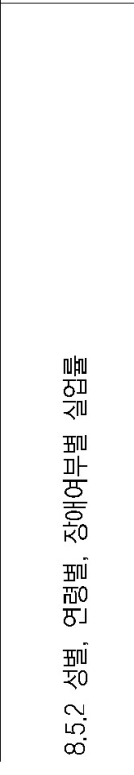 & 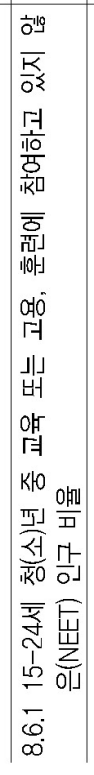 & 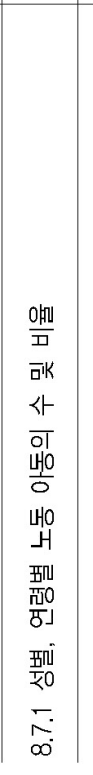 & & 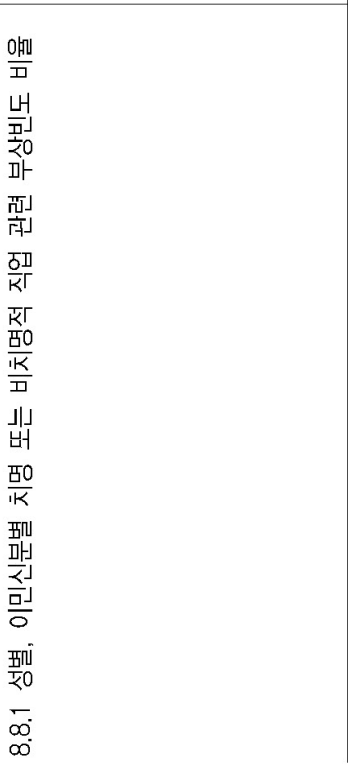 & 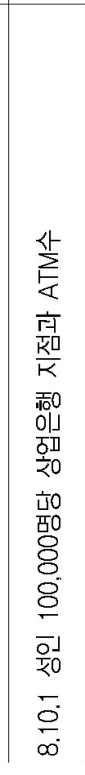 & 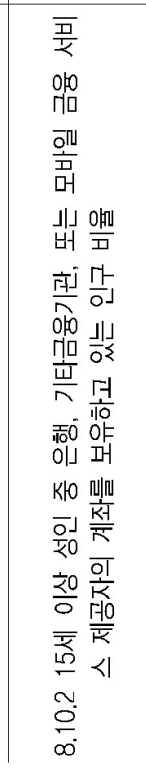 \\
\hline
\end{tabular}

제 I 장

제 II 장

섹

터

제 III 장 


\begin{tabular}{|c|c|c|c|c|c|c|c|c|c|c|c|c|c|}
\hline 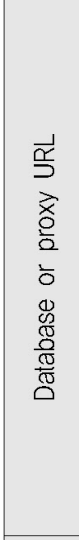 & 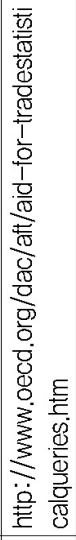 & 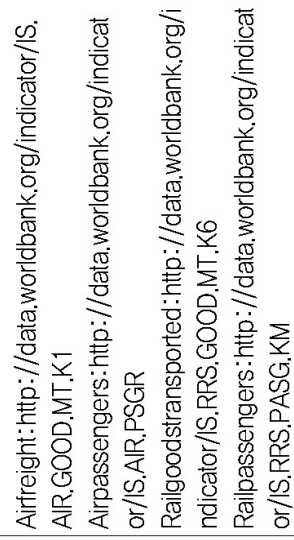 & 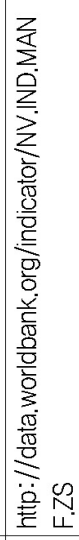 & 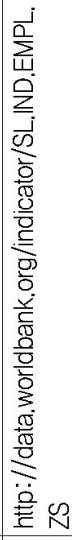 & 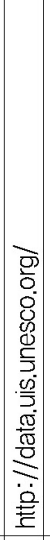 & 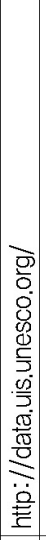 & 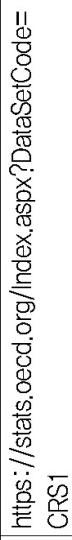 & 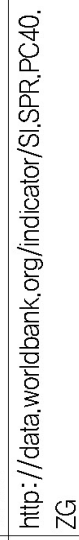 & 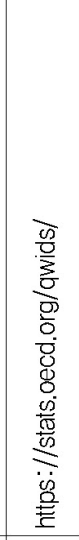 & 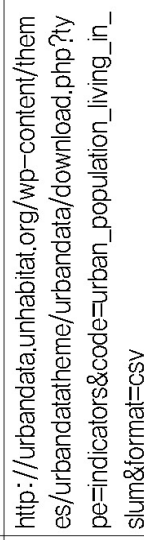 & 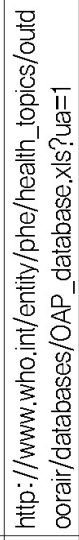 & 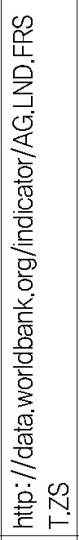 & 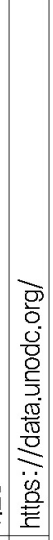 \\
\hline 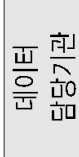 & $\begin{array}{l}0 \\
0 \\
0 \\
0 \\
0 \\
\text { Ü }\end{array}$ & $\begin{array}{l}\text { 돓 } \\
\text { Ф } \\
\text { 읗 } \\
\stackrel{0}{3}\end{array}$ & 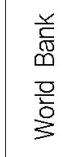 & 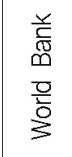 & 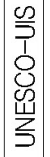 & 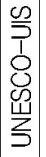 & $\begin{array}{l}0 \\
0 \\
0 \\
0 \\
0 \\
\text { Ü }\end{array}$ & 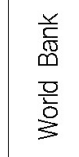 & 占 & 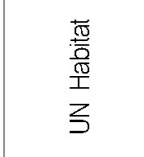 & 울 & 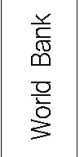 & $\begin{array}{l}0 \\
0 \\
0 \\
3\end{array}$ \\
\hline 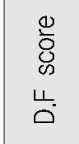 & $\begin{array}{l}\overline{8} \\
\overline{8} \\
\frac{7}{9}\end{array}$ & $\begin{array}{l}\overline{8} \\
8 \\
0 \\
z \\
\overline{0}\end{array}$ & $\begin{array}{l}\overline{8} \\
\dot{8} \\
\frac{2}{9}\end{array}$ & $\begin{array}{l}\overline{8} \\
8 \\
8 \\
\frac{0}{5} \\
\frac{1}{\sigma}\end{array}$ & \begin{tabular}{|l|} 
\\
\\
8 \\
0 \\
$\frac{1}{5}$ \\
$\frac{1}{5}$
\end{tabular} & $\begin{array}{l}\overline{8} \\
\frac{1}{2} \\
\frac{1}{5} \\
\frac{5}{\sigma}\end{array}$ & $\begin{array}{l}\overline{8} \\
8 \\
\overline{8} \\
\frac{2}{9}\end{array}$ & $\begin{array}{l}\overline{8} \\
\frac{8}{2} \\
\frac{2}{9}\end{array}$ & $\begin{array}{l}\overline{8} \\
8 \\
\frac{0}{9} \\
\frac{1}{3}\end{array}$ & $\begin{array}{l}\frac{1}{8} \\
\frac{\alpha}{9}\end{array}$ & $\begin{array}{l}\frac{2}{8} \\
\frac{8}{2} \\
\frac{1}{3}\end{array}$ & 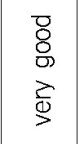 & 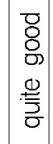 \\
\hline ㄴ. & 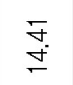 & $\frac{\nabla}{\dot{m}}$ & $\begin{array}{l}\stackrel{\infty}{\infty} \\
\stackrel{m}{-}\end{array}$ & $\frac{\nabla}{\sigma}$ & $\begin{array}{l}\infty \\
\infty \\
\infty \\
\sigma \\
\infty\end{array}$ & $\therefore$ & $\begin{array}{l}\underset{f}{\forall} \\
\underset{\forall}{*}\end{array}$ & - & $\begin{array}{l}\underset{f}{+} \\
\underset{J}{*}\end{array}$ & $\stackrel{\llcorner\infty}{\infty}$ & - & 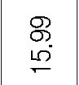 & $\begin{array}{l}\bar{\sigma} \\
\infty \\
\infty\end{array}$ \\
\hline $\begin{array}{l}0 \\
\overline{0} \\
0 \\
0 \\
0\end{array}$ & $\begin{array}{l}\overline{8} \\
8 \\
0 \\
0 \\
\overline{\bar{\sigma}}\end{array}$ & $\begin{array}{l}8 \\
8 \\
8 \\
z \\
3\end{array}$ & $\begin{array}{l}\overline{8} \\
8 \\
\grave{1} \\
\grave{3}\end{array}$ & $\begin{array}{l}\overline{8} \\
8 \\
\overline{0} \\
>0\end{array}$ & \begin{tabular}{|l|}
$\overline{8}$ \\
8 \\
$\overline{0}$ \\
$\frac{0}{5}$ \\
$\bar{\sigma}$
\end{tabular} & 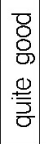 & $\begin{array}{l}\overline{8} \\
8 \\
\frac{8}{9}\end{array}$ & $\begin{array}{l}\grave{\overline{0}} \\
\frac{8}{2} \\
\frac{0}{5} \\
\frac{3}{0}\end{array}$ & $\begin{array}{l}8 \\
8 \\
8 \\
\frac{1}{9}\end{array}$ & $\begin{array}{l}\bar{z} \\
8 \\
\frac{9}{3} \\
\frac{3}{0}\end{array}$ & 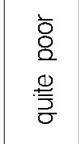 & $\begin{array}{l}\overline{8} \\
8 \\
8 \\
\overline{9}\end{array}$ & $\begin{array}{l}8 \\
8 \\
8 \\
2 \\
9 \\
9\end{array}$ \\
\hline$0 \longdiv { 0 }$ & $\stackrel{\circ}{\circ}$ & $\frac{2^{0}}{\infty}$ & $\frac{\circ}{\circ}$ & ळ̊ & 号 & 号 & 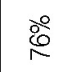 & 䨞 & $\gtreqless$ & $\stackrel{\circ}{\Im}$ & 号 & $\stackrel{\circ}{\circ}$ & 吕 \\
\hline 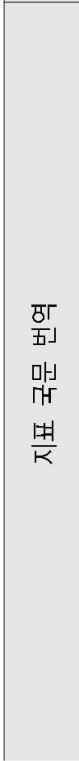 & 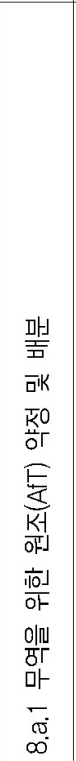 & 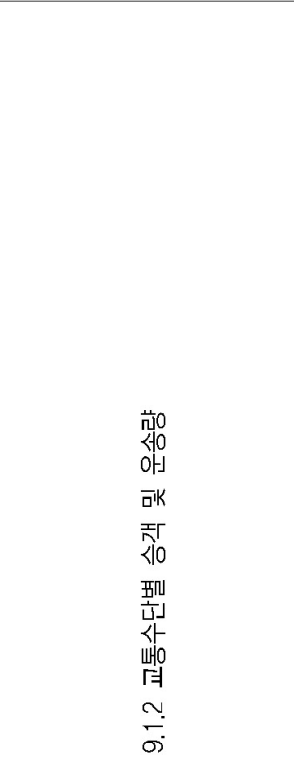 & 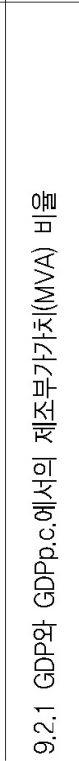 & 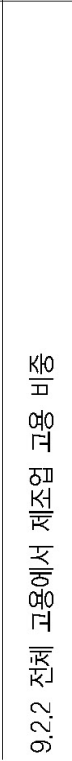 & 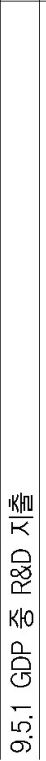 & 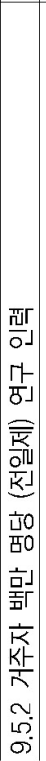 & 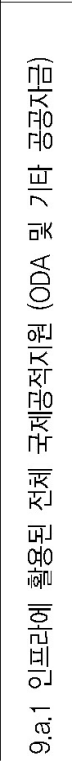 & 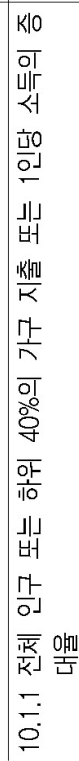 & 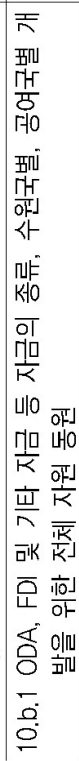 & 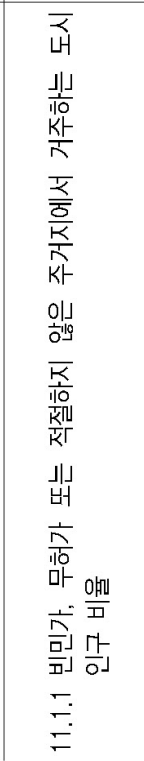 & 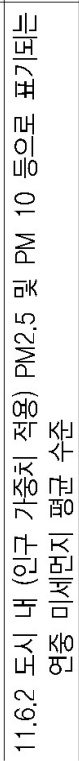 & 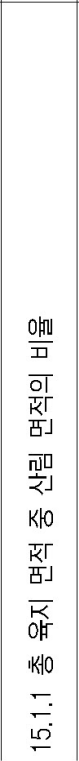 & 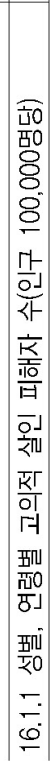 \\
\hline
\end{tabular}




\begin{tabular}{|c|c|c|c|c|c|c|c|c|c|c|c|c|c|c|c|}
\hline 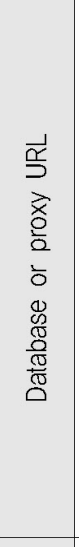 & 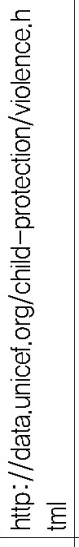 & 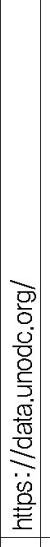 & 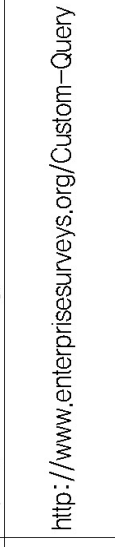 & 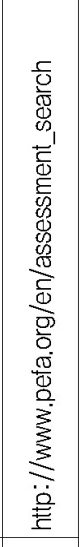 & 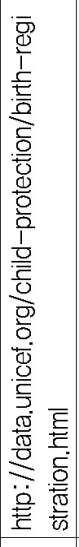 & 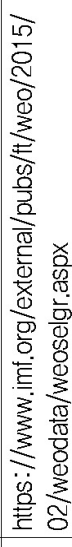 & 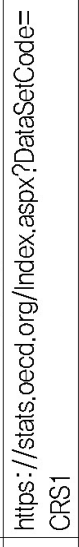 & 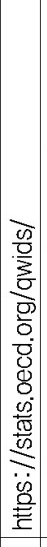 & 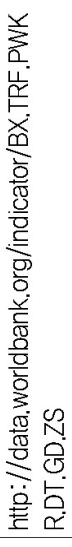 & 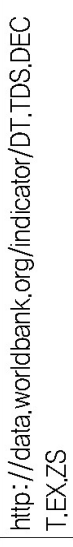 & 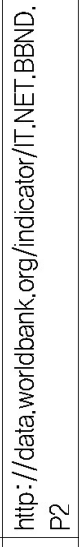 & 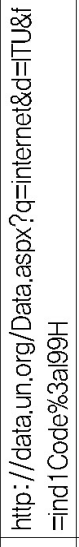 & 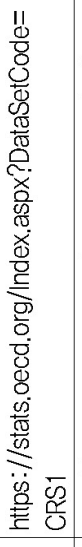 & 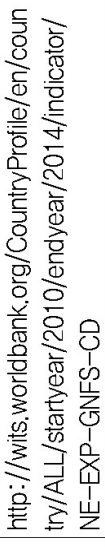 & \\
\hline 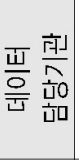 & 岀 & 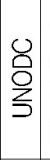 & 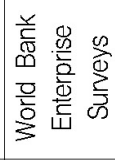 & 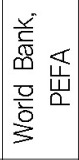 & 岀 & 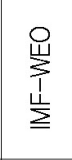 & $\begin{array}{l}0 \\
0 \\
1 \\
1 \\
0 \\
\text { 岁 }\end{array}$ & $\begin{array}{c}0 \\
1 \\
0 \\
1 \\
0 \\
0 \\
0 \\
0\end{array}$ & $\begin{array}{l}\text { 帝 } \\
\text { m } \\
\text { 믛 } \\
\text { 今े }\end{array}$ & 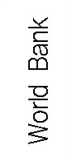 & $\begin{array}{l}\text { 듬 } \\
\Phi \\
\infty \\
\text { 믛 } \\
\dot{3}\end{array}$ & $\begin{array}{l}\frac{\sqrt{0}}{\mathrm{D}} \\
0 \\
\vdots\end{array}$ & 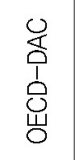 & $\stackrel{5}{3}$ & \\
\hline $\begin{array}{l}0 \\
\frac{0}{2} \\
\infty \\
4 \\
\end{array}$ & $\begin{array}{l}\overline{8} \\
\frac{2}{2} \\
\bar{y}\end{array}$ & $\begin{array}{l}\overline{8} \\
8 \\
\frac{0}{2} \\
\frac{1}{5}\end{array}$ & $\begin{array}{l}\overline{8} \\
8 \\
\frac{2}{9}\end{array}$ & $\begin{array}{l}\overline{8} \\
8 \\
\frac{8}{9}\end{array}$ & $\begin{array}{l}\overline{8} \\
\frac{1}{2} \\
\overline{1} \\
0\end{array}$ & $\begin{array}{l}\overline{8} \\
8 \\
\frac{8}{9}\end{array}$ & $\begin{array}{l}\overline{8} \\
8 \\
0 \\
\frac{2}{9} \\
3\end{array}$ & $\begin{array}{l}8 \\
8 \\
8 \\
2 \\
\frac{8}{9}\end{array}$ & $\begin{array}{l}\frac{7}{8} \\
\frac{0}{2} \\
\frac{2}{9}\end{array}$ & $\begin{array}{l}\overline{8} \\
8 \\
0 \\
\frac{2}{9}\end{array}$ & $\begin{array}{l}\overline{8} \\
8 \\
\frac{0}{0} \\
\frac{0}{\sigma}\end{array}$ & $\begin{array}{l}\overline{8} \\
8 \\
\frac{0}{3} \\
\frac{1}{3}\end{array}$ & $\begin{array}{l}8 \\
8 \\
0 \\
\frac{7}{9}\end{array}$ & $\begin{array}{l}\overline{8} \\
8 \\
0 \\
\frac{0}{9} \\
3\end{array}$ & \\
\hline$\stackrel{u}{\circ}: \stackrel{\bar{D}}{=}$ & - & 岂 & $\stackrel{\square}{\sigma}$ & $\cong$ & - & 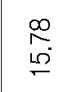 & $\begin{array}{l}\bar{f} \\
\dot{\forall}\end{array}$ & $\begin{array}{l}\bar{y} \\
\dot{v}\end{array}$ & $\begin{array}{l}\underset{p}{p} \\
\stackrel{p}{0}\end{array}$ & $\stackrel{\infty}{\stackrel{\infty}{\grave{m}}}$ & $\begin{array}{l}\stackrel{?}{\risingdotseq} \\
=\end{array}$ & $\begin{array}{l}\stackrel{g}{g} \\
\underset{\forall}{+}\end{array}$ & 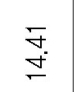 & 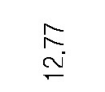 & \\
\hline $\begin{array}{l}0 \\
\stackrel{0}{0} \\
0 \\
0 \\
ن\end{array}$ & $\begin{array}{l}\bar{z} \\
8 \\
\frac{9}{5} \\
\frac{3}{\sigma}\end{array}$ & $\begin{array}{l}\overline{8} \\
8 \\
0 \\
\frac{0}{5} \\
\overline{0}\end{array}$ & $\begin{array}{l}\overline{8} \\
\overline{8} \\
\frac{0}{\bar{y}} \\
\overline{\bar{\sigma}}\end{array}$ & $\begin{array}{l}\frac{1}{o} \\
\frac{8}{2} \\
\frac{9}{\bar{\sigma}}\end{array}$ & $\begin{array}{l}\overline{8} \\
8 \\
8 \\
\frac{8}{9}\end{array}$ & $\begin{array}{l}8 \\
8 \\
8 \\
8 \\
\end{array}$ & $\begin{array}{l}8 \\
8 \\
0 \\
\frac{9}{9}\end{array}$ & $\begin{array}{l}8 \\
8 \\
8 \\
2 \\
\frac{1}{9}\end{array}$ & $\begin{array}{l}\overline{8} \\
8 \\
\frac{8}{9}\end{array}$ & $\begin{array}{l}\overline{8} \\
8 \\
0 \\
\frac{0}{5} \\
\frac{y}{0}\end{array}$ & $\begin{array}{l}8 \\
8 \\
8 \\
\frac{8}{9}\end{array}$ & $\begin{array}{l}\overline{8} \\
8 \\
8 \\
\frac{10}{1}\end{array}$ & $\begin{array}{l}\overline{8} \\
8 \\
\frac{8}{9}\end{array}$ & $\begin{array}{l}\overline{8} \\
8 \\
2 \\
\frac{8}{9}\end{array}$ & \\
\hline$u \widehat{o}$ & $\frac{\circ}{m}$ & 今̊ & $\stackrel{8}{\stackrel{2}{2}}$ & 号 & $\begin{array}{l}\stackrel{\circ}{\circ} \\
\text { ळ. }\end{array}$ & 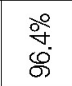 & @ & 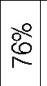 & 吕 & 今̊ & $\stackrel{\circ}{\circ}$ & 今̊응 & @o & $\frac{\circ}{\sigma}$ & \\
\hline 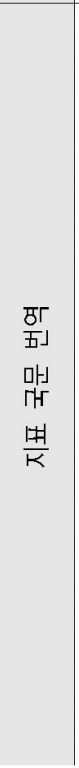 & 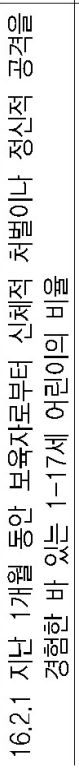 & 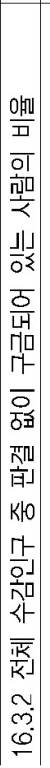 & 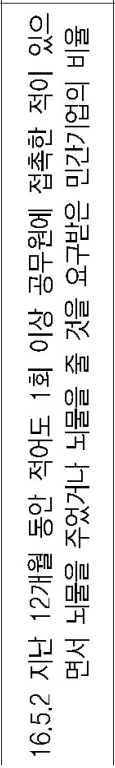 & 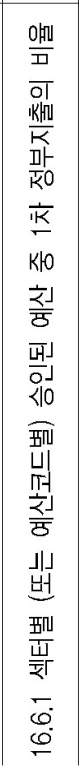 & 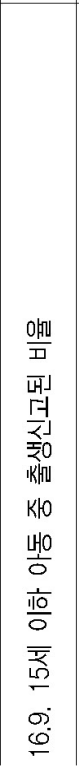 & 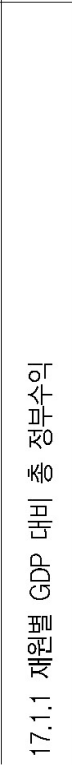 & 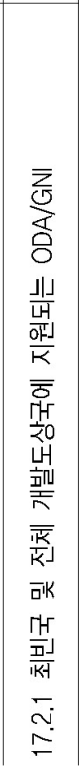 & 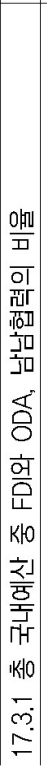 & 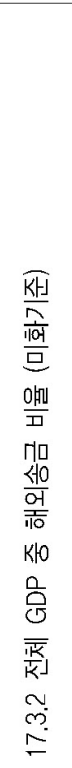 & 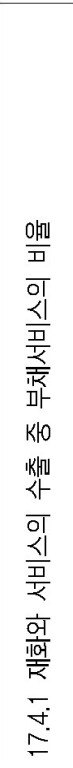 & 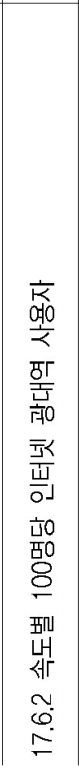 & 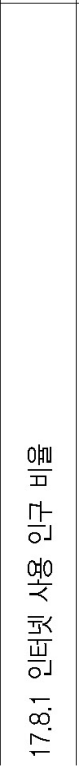 & 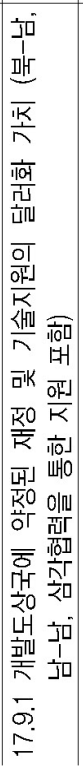 & 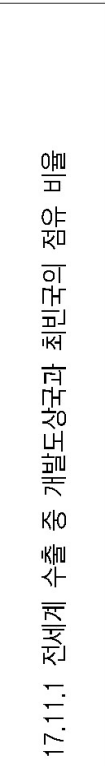 & 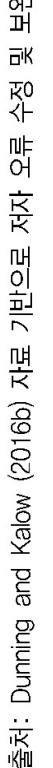 \\
\hline
\end{tabular}

제 I 장

제 II 장

섹

터

제 III장 